\title{
Controlling One-Electron vs Two-Electron Pathways in the Multi-Electron Redox Cycle of Nickel Diethyldithiocarbamate
}

Md. Motiur R. Mazumder, Andricus Burton, Chase S. Richburg, Soumen Saha ${ }^{\dagger}$, Bryan Cronin, Evert Duin, Byron H. Farnum*

Department of Chemistry and Biochemistry, Auburn University, Auburn, AL 36849

*corresponding author

†present address: Department of Chemistry, University of Utah, Salt Lake City, UT 84112

\section{Abstract}

The unique redox cycle of $\mathrm{Ni}^{\mathrm{II}}(\mathrm{dtc})_{2}$, where $\mathrm{dtc}^{-}$is $N, N$-diethyldithiocarbamate, in acetonitrile displays $2 \mathrm{e}^{-}$redox chemistry upon oxidation from $\mathrm{Ni}^{\mathrm{II}}(\mathrm{dtc})_{2} \rightarrow\left[\mathrm{Ni}^{\mathrm{IV}}(\mathrm{dtc})_{3}\right]^{+}$but $1 \mathrm{e}^{-}$redox chemistry upon reduction from $\left[\mathrm{Ni}^{\mathrm{IV}}(\mathrm{dtc})_{3}\right]^{+} \rightarrow \mathrm{Ni}^{\mathrm{III}}(\mathrm{dtc})_{3} \rightarrow \mathrm{Ni}^{\mathrm{II}}(\mathrm{dtc})_{2}$. The underlying reasons for this cycle lie in the structural changes that occur between four-coordinate $\mathrm{Ni}^{\mathrm{II}}(\mathrm{dtc})_{2}$ and sixcoordinate $\left[\mathrm{Ni}^{\mathrm{IV}}(\mathrm{dtc})_{3}\right]^{+}$. Cyclic voltammetry $(\mathrm{CV})$ experiments show that these $1 \mathrm{e}^{-}$and $2 \mathrm{e}^{-}$ pathways can be controlled by the addition of pyridine-based ligands (L) to the electrolyte solution. Specifically, the addition of these ligands resulted in a $1 \mathrm{e}^{-}$ligand-coupled electron transfer (LCET) redox wave which produced a mixture of pyridine-bound $\mathrm{Ni}(\mathrm{III})$ complexes, $\left[\mathrm{Ni}^{\mathrm{III}}(\mathrm{dtc})_{2}(\mathrm{~L})\right]^{+}$and $\left[\mathrm{Ni}^{\mathrm{III}}(\mathrm{dtc})_{2}(\mathrm{~L})_{2}\right]^{+}$. Although the complexes could not be isolated, electron paramagnetic resonance (EPR) measurements using a chemical oxidant in the presence of 4-methoxypyridine confirmed the formation of trans $-\left[\mathrm{Ni}^{\mathrm{IIII}}(\mathrm{dtc})_{2}(\mathrm{~L})_{2}\right]^{+}$. Density functional theory calculations were also used to support the formation of pyridine coordinated $\mathrm{Ni}$ (III) complexes through structural optimization and calculation of EPR parameters. The reversibility of the LCET process was found to be dependent on both the basicity of the pyridine ligand and the scan rate of the $\mathrm{CV}$ experiment. For strongly basic pyridines (e.g. 4-methoxypyridine) and/or fast scan rates, high reversibility was achieved, allowing $\left[\mathrm{Ni}^{\mathrm{III}}(\mathrm{dtc})_{2}(\mathrm{~L})_{\mathrm{x}}\right]^{+}$to be reduced directly back to $\mathrm{Ni}^{\mathrm{II}}(\mathrm{dtc})_{2}+\mathrm{xL}$. For weakly basic pyridines (e.g. 3-bromopyridine) and/or slow scan rates, $\left[\mathrm{Ni}^{\mathrm{III}}(\mathrm{dtc})_{2}(\mathrm{~L})_{\mathrm{x}}\right]^{+}$decayed irreversibly to form $\left[\mathrm{Ni}^{\mathrm{IV}}(\mathrm{dtc})_{3}\right]^{+}$. Detailed kinetics studies using $\mathrm{CV}$ reveal that $\left[\mathrm{Ni}^{\mathrm{III}}(\mathrm{dtc})_{2}(\mathrm{~L})\right]^{+}$ and $\left[\mathrm{Ni}^{\mathrm{III}}(\mathrm{dtc})_{2}(\mathrm{~L})_{2}\right]^{+}$decay by parallel pathways due to a small equilibrium between the two species. The rate constants for ligand dissociation $\left(\left[\mathrm{Ni}^{\mathrm{III}}(\mathrm{dtc})_{2}(\mathrm{~L})_{2}\right]^{+} \rightarrow\left[\mathrm{Ni}^{\mathrm{III}}(\mathrm{dtc})_{2}(\mathrm{~L})\right]^{+}+\mathrm{L}\right)$ along with decomposition of $\left[\mathrm{Ni}^{\mathrm{III}}(\mathrm{dtc})_{2}(\mathrm{~L})\right]^{+}$and $\left[\mathrm{Ni}^{\mathrm{III}}(\mathrm{dtc})_{2}(\mathrm{~L})_{2}\right]^{+}$species were found to increase with 
the electron-withdrawing character of the pyridine ligand, indicating pyridine dissociation is likely the rate limiting step for decomposition of these complexes. These studies establish a general trend for kinetically trapping $1 \mathrm{e}^{-}$intermediates along a $2 \mathrm{e}^{-}$oxidation path.

Key words: multi-electron transfer, nickel, dithiocarbamate, ligand coupled electron transfer, nickel(III) 


\section{Introduction}

Multi-electron redox couples play a significant role in many biological and energy conversion/storage processes. ${ }^{1-7}$ These reactions are often achieved through proton-coupled electron transfer (PCET) where protonation of reduced molecules results in a condition of potential inversion. This can be seen for the case of the $\mathrm{O}_{2} / \mathrm{H}_{2} \mathrm{O}$ redox couple where the redox potential of the $2 \mathrm{e}^{-} \mathrm{H}_{2} \mathrm{O}_{2} / \mathrm{H}_{2} \mathrm{O}$ couple (1.76 V vs RHE) is more positive than the $2 \mathrm{e}^{-} \mathrm{O}_{2} / \mathrm{H}_{2} \mathrm{O}_{2}$ couple $(-0.68 \mathrm{~V}$ vs RHE), resulting in disproportionation of the $\mathrm{H}_{2} \mathrm{O}_{2}$ intermediate and an overall $4 \mathrm{e}$ - redox couple at $1.23 \mathrm{~V}$ vs RHE. A similar scenario can be described for the $2 \mathrm{e}^{-}$quinone/hydroquinone redox couple wherein protonation of hydroquinone results in disproportionation of the $1 \mathrm{e}^{-}$semiquinone intermediate. ${ }^{4,5,8}$

By contrast, transition metal complexes achieve multi-electron redox activity through ligandcoupled electron transfer (LCET) reactions whereby ligand coordination to the metal center is coupled to oxidation and ligand dissociation is coupled to reduction. Importantly, not all LCET reactions result in multi-electron redox activity. There are many examples of ligand induced shifts in metal-based redox potentials for molecules such as metalloporphyrins; however, in these examples, the thermodynamics for ligand association/dissociation for the oxidized and reduced metal center is not large enough to result in potential inversion. ${ }^{9-11}$ Organometallic reactions such as oxidative addition and reductive elimination are prime examples of multi-electron LCET reactions. In these examples, $2 \mathrm{e}^{-}$oxidation/reduction of the metal is accompanied by intermolecular oxidation/reduction of the incoming/outgoing ligands. Another important type of multi-electron LCET reactivity includes transition metal complexes where intramolecular ligand association/dissociation is used to achieve $2 \mathrm{e}^{-}$oxidation/reduction of the metal center. ${ }^{12-14}$ These types of molecules could have applications as outer-sphere $2 \mathrm{e}^{-}$reductants/oxidants as well as catholytes/anolytes in redox-flow batteries. The latter case of multi-electron LCET reactivity is much rarer than the former and therefore understanding the mechanisms which drive these reactions could lead to new examples of LCET reactivity.

$\mathrm{Ni}^{\mathrm{II}}(\mathrm{dtc})_{2}$, where $\mathrm{dtc}^{-}$is $\mathrm{N}, \mathrm{N}$-diethyldithiocarbamate, is an interesting example of an intermolecular $2 \mathrm{e}^{-}$LCET redox cycle shown in Scheme 1. ${ }^{15-17}$ Oxidation from $\mathrm{Ni}^{\mathrm{II}}(\mathrm{dtc})_{2}$ to $\left[\mathrm{Ni}^{\mathrm{IV}}(\mathrm{dtc})_{3}\right]^{+}$involves an increase in coordination number from 4 to 6 provided by a third $\mathrm{dtc}^{-}$ ligand derived through intermolecular ligand exchange from a secondary $\mathrm{Ni}^{\mathrm{II}}(\mathrm{dtc})_{2}$ molecule, $\mathrm{K}_{3}$ in Scheme 1. 16,18 This ligand exchange reaction generates potential inversion between the $1 \mathrm{e}^{-}$ 
$\left[\mathrm{Ni}^{\mathrm{IV} / I I I}(\mathrm{dtc})_{3}\right]^{+/ 0}$ redox couple $\left(-0.24 \mathrm{~V}\right.$ vs $\left.\mathrm{Fc}^{+/ 0}\right)$ and the $1 \mathrm{e}^{-}\left[\mathrm{Ni}^{\mathrm{III/II}}(\mathrm{dtc})_{2}\right]^{+/ 0}$ redox potential $(0.25$ $\mathrm{V}$ vs $\left.\mathrm{Fc}^{+/ 0}\right)$, resulting in a formal $2 \mathrm{e}^{-}$reduction potential for the $\left[\mathrm{Ni}^{\mathrm{iV}}(\mathrm{dtc})_{3}\right]^{+} / \mathrm{Ni}^{\mathrm{II}}(\mathrm{dtc})_{2}$ couple at $0.01 \mathrm{~V} \mathrm{vs} \mathrm{Fc}^{+/ 0}$ in acetonitrile (MeCN), Equation 1.

$$
\begin{aligned}
& E_{4}^{o}=-0.24 \mathrm{~V} \quad E_{3}^{o}=-0.71 \mathrm{~V} \\
& {\left[\mathrm{Ni}^{i \mathrm{~V}}(\mathrm{dtc})_{3}\right]^{+} \rightleftarrows \mathrm{Nill}^{\prime \prime}(\mathrm{dtc})_{3} \rightleftarrows\left[\mathrm{Ni}^{\prime \prime}(\mathrm{dtc})_{3}\right]^{-}} \\
& \downarrow K_{4} \gg 1 \quad\left|\uparrow K_{3} \sim 1 \quad\right|_{\uparrow} K_{2} \ll 1 \\
& {\left[\mathrm{Ni}(\mathrm{dtc})_{2}\right]^{2+} \rightleftarrows\left[\mathrm{Ni}^{\prime \prime \prime}(\mathrm{dtc})_{2}\right]^{+} \rightleftarrows \mathrm{Ni}^{\prime \prime}(\mathrm{dtc})_{2}} \\
& E^{\circ}{ }_{2} \quad E_{1}^{o}=0.25 \mathrm{~V}
\end{aligned}
$$

Scheme 1. Thermochemical cycle describing the electron transfer (horizontal) and ligand transfer (vertical) reactions involved in the $\left[\mathrm{Ni}^{\mathrm{iV}}(\mathrm{dtc})_{3}\right]^{+} / \mathrm{Ni}^{\mathrm{II}}(\mathrm{dtc})_{2}$ redox couple. ${ }^{17}$ All potentials are reported versus ferrocene $\left(\mathrm{Fc}^{+/ 0}\right)$.

1) $\quad\left[\mathrm{Ni}^{\mathrm{IV}}(\mathrm{dtc})_{3}\right]^{+}+1 / 2 \mathrm{Ni}^{\mathrm{II}}+2 \mathrm{e}^{-} \rightarrow 3 / 2 \mathrm{Ni}^{\mathrm{II}}(\mathrm{dtc})_{2}$

There are two reasons for potential inversion in the $\left[\mathrm{Ni}^{\mathrm{iV}}(\mathrm{dtc})_{3}\right]^{+} / \mathrm{Ni}^{\mathrm{II}}(\mathrm{dtc})_{2}$ redox couple: (1) the natural occupancy of d-orbitals as a function of nickel oxidation state and (2) the resonance character of the $\mathrm{dtc}^{-}$ligand. The $\mathrm{d}^{8}$ configuration of $\mathrm{Ni}(\mathrm{II})$ coupled with $\mathrm{dtc}^{-}$ligands yields a fourcoordinate, square planar structure which is strongly resistant toward axial coordination. ${ }^{19-23}$ Notably, other first-row transition metals such as $\mathrm{Mn}(\mathrm{II}), \mathrm{Fe}(\mathrm{II})$, and $\mathrm{Co}(\mathrm{II})$ readily form [M(dtc) $\left.{ }_{3}\right]^{-}$ complexes. ${ }^{24,25}$ Upon oxidation, the $\mathrm{d}^{6}$ configuration of $\mathrm{Ni}(\mathrm{IV})$ strongly favors a six-coordinate environment, thus promoting LCET. ${ }^{11,26,27}$ Indeed, the conversion between $\mathrm{d}^{6}$ and $\mathrm{d}^{8}$ electron configurations is paramount to LCET examples found in the literature. ${ }^{12-14}$ The dithiocarbamate ligand resonance capability is also an important feature in its ability to support both $\mathrm{Ni}$ (II) and $\mathrm{Ni}(\mathrm{IV}) .{ }^{28}$ Fackler has suggested that the ability of dtc ${ }^{-}$ligands to shift electron density onto the sulfur atoms is responsible for its stability of high valent $\mathrm{Ni}(\mathrm{IV}) .{ }^{32} \mathrm{X}$-ray crystallography and FTIR data show a compression of the $\mathrm{C}-\mathrm{N}$ bond for $\left[\mathrm{Ni}^{\mathrm{IV}^{\mathrm{V}}}\left(n-\mathrm{Bu}_{2} \mathrm{dtc}\right)_{3}\right]^{+}$with respect to $\mathrm{Ni}^{\mathrm{II}}\left(n-\mathrm{Bu}_{2} \mathrm{dtc}\right)_{2}$, suggesting stronger double bond character and higher electron density on the sulfur atoms. ${ }^{29,30}$

The electrochemistry of $\mathrm{Ni}^{\mathrm{II}}(\mathrm{dtc})_{2}$ in $\mathrm{MeCN}$ has been previously studied in the literature by our group and others. ${ }^{16,17,31}$ The redox cycle is notable in that $\mathrm{Ni}^{\mathrm{II}}(\mathrm{dtc})_{2}$ undergoes $2 \mathrm{e}^{-}$oxidation to 
$\left[\mathrm{Ni}^{\mathrm{IV}}(\mathrm{dtc})_{3}\right]^{+}$according to an ECE-DISP1 $(\mathrm{E}=$ electron transfer step, $\mathrm{C}=$ chemical step, DISP $=$ disproportionation) mechanism, Equation 2-5. The DISP1 modifier indicates that the chemical step is rate limiting for the production of $\mathrm{Ni}^{\mathrm{III}}(\mathrm{dtc})_{3}$ and thus the disproportionation step is the primary pathway for the production of $\left[\mathrm{Ni}^{\mathrm{IV}}(\mathrm{dtc})_{3}\right]^{+}$, as opposed to direct oxidation of $\mathrm{Ni}^{\mathrm{III}}(\mathrm{dtc})_{3}$ at the electrode surface. Reduction of $\left[\mathrm{Ni}^{\mathrm{IV}}(\mathrm{dtc})_{3}\right]^{+}$back to $\mathrm{Ni}^{\mathrm{II}}(\mathrm{dtc})_{2}$ occurs through two separate $1 \mathrm{e}^{-}$ reductions of $\left[\mathrm{Ni}^{\mathrm{IV}}(\mathrm{dtc})_{3}\right]^{+}$to $\mathrm{Ni}^{\mathrm{III}}(\mathrm{dtc})_{3}$ via outer-sphere electron transfer, Equation 6, and $\mathrm{Ni}^{\mathrm{III}}(\mathrm{dtc})_{3}$ to $\mathrm{Ni}^{\mathrm{II}}(\mathrm{dtc})_{2}$ via an EC mechanism, Equation 7-8. Digital simulations of cyclic voltammograms as a function of scan rate using the mechanism of Equations 2-8 have shown excellent agreement with observed data. ${ }^{17}$

\section{Oxidation:}
2) $\mathrm{Ni}^{\mathrm{II}}(\mathrm{dtc})_{2} \rightarrow\left[\mathrm{Ni}^{\mathrm{III}}(\mathrm{dtc})_{2}\right]^{+}+\mathrm{e}^{-}$
E
3) $2\left[\mathrm{Ni}^{\mathrm{III}}(\mathrm{dtc})_{2}\right]^{+}+\mathrm{Ni}^{\mathrm{II}}(\mathrm{dtc})_{2} \rightleftharpoons 2 \mathrm{Ni}^{\mathrm{III}}(\mathrm{dtc})_{3}+\mathrm{Ni}^{\mathrm{II}}$
C
4) $\mathrm{Ni}^{\mathrm{III}}(\mathrm{dtc})_{3} \rightarrow\left[\mathrm{Ni}^{\mathrm{iV}}(\mathrm{dtc})_{3}\right]^{+}+\mathrm{e}^{-}$
E
5) $\left[\mathrm{Ni}^{\mathrm{III}}(\mathrm{dtc})_{2}\right]^{+}+\mathrm{Ni}^{\mathrm{III}}(\mathrm{dtc})_{3} \rightarrow \mathrm{Ni}^{\mathrm{II}}(\mathrm{dtc})_{2}+\left[\mathrm{Ni}^{\mathrm{IV}}(\mathrm{dtc})_{3}\right]^{+}$
DISP

\section{Reduction:}

6) $\left[\mathrm{Ni}^{\mathrm{IV}}(\mathrm{dtc})_{3}\right]^{+}+\mathrm{e}^{-} \rightarrow \mathrm{Ni}^{\mathrm{III}}(\mathrm{dtc})_{3}$

E

7) $\mathrm{Ni}^{\mathrm{III}}(\mathrm{dtc})_{3}+\mathrm{e}^{-} \rightarrow\left[\mathrm{Ni}^{\mathrm{II}}(\mathrm{dtc})_{3}\right]^{-}$

E

8) $2\left[\mathrm{Ni}^{\mathrm{II}}(\mathrm{dtc})_{3}\right]^{-}+\mathrm{Ni}^{\mathrm{II}} \rightarrow 3 \mathrm{Ni}^{\mathrm{II}}(\mathrm{dtc})_{2}$

C

According to Scheme 1, the ligand exchange reaction shown in Equation 3 is an important step in both oxidation of $\mathrm{Ni}^{\mathrm{II}}(\mathrm{dtc})_{2}$ and reduction of $\mathrm{Ni}^{\mathrm{III}}(\mathrm{dtc})_{3}$. The facilitation of this reaction in the forward direction to form $\mathrm{Ni}^{\mathrm{III}}(\mathrm{dtc})_{3}$ allows for $2 \mathrm{e}^{-}$oxidation to proceed; however, the lack of reactivity in the reverse direction forces reduction to occur through sequential $1 \mathrm{e}^{-}$steps. The details of this reaction are not currently well understood and likely involve the formation of dimeric species to facilitate ligand exchange. We previously studied the influence of pyridine on the multielectron redox cycle of $\mathrm{Ni}^{\mathrm{II}}(\mathrm{dtc})_{2}$, as the coordination environment of the $\mathrm{Ni}(\mathrm{III})$ oxidation state is greatly important in understanding the kinetic and thermodynamic factors that dictate $2 \mathrm{e}^{-}$ versus $1 \mathrm{e}^{-}$redox chemistry. ${ }^{17}$ The addition of pyridine was shown to trap Ni(III) intermediates on the time scale of the cyclic voltammetry (CV) experiment and allow for mechanistic information 
to be gleaned from the decomposition of these Ni(III)-pyridine species. The present study represents an extended electrochemical study using multiple derivatized pyridine ligands (L) in order to study their general effect on the multielectron redox cycle of $\mathrm{Ni}^{\mathrm{II}}(\mathrm{dtc})_{2}$. The addition of these pyridines shows the ability to trap intermediate $\mathrm{Ni}(\mathrm{III})$ oxidation states prior to ligand exchange and subsequent oxidation to $\mathrm{Ni}(\mathrm{IV})$. Rate constants for ligand exchange are estimated from CV studies while electron paramagnetic resonance (EPR) measurements and computational studies provide further insight and support for coordination of $\mathrm{L}$ to the $\mathrm{Ni}(\mathrm{III})$ metal center.

\section{Experimental}

Synthesis and Characterization $\mathrm{Ni}^{\mathrm{II}}(\mathrm{dtc})_{2}$ was synthesized by adding two equivalents of sodium diethyldithiocarbamate trihydrate (Sigma-Aldrich, >99\%) to one equivalent of nickel(II) chloride hexahydrate (Alfa Aesar, 98\%) in water (Millipore, $18 \mathrm{M} \Omega$ ) as described previously in the literature. ${ }^{16,17}$ A light green solid precipitated instantly and was filtered under vacuum, washed with cold distilled water, absolute ethanol (KOPTEC, 200 proof), and diethyl ether (99\%, sigma aldrich) with $96 \%$ yield. Solid product was kept in a vacuum oven (VWR, $1.003 \mathrm{~atm}, 60^{\circ} \mathrm{C}$ ) until ready for use. Characterization of the light green solid was performed by ${ }^{1} \mathrm{H}-\mathrm{NMR}$ (acetonitrile$\mathrm{d}_{3}$, Cambridge Isotope Laboratories): $\delta 3.57\left(\mathrm{q},-\mathrm{CH}_{2}-\right), 1.17\left(\mathrm{t},-\mathrm{CH}_{3}\right)$ and UV-Vis spectroscopy $\left(\lambda_{\max }=388 \mathrm{~nm}\left(5,600 \mathrm{M}^{-1} \mathrm{~cm}^{-1}\right)\right.$ and $\left.\lambda_{\max }=323 \mathrm{~nm}\left(26,700 \mathrm{M}^{-1} \mathrm{~cm}^{-1}\right)\right)$.

Electrochemistry Absolute ethanol was used to recrystallize tetrabutylammonium hexafluorophosphate ( $\mathrm{TBAPF}_{6}$, Sigma-Aldrich, 98\%), then dehydrated under vacuum, and kept in a vacuum oven for storage. All cyclic voltammetry experiments were performed with $0.1 \mathrm{M}$ $\mathrm{TBAPF}_{6}$ in acetonitrile (HPLC grade, VWR) as the electrolyte in a nitrogen-purged environment at room temperature. Experiments were performed using a WaveDriver 20 bipotentiostat (Pine Research) with a glassy-carbon-disk (GC) working electrode (5 mm diameter, Pine Research), a $\mathrm{Ag} / \mathrm{Ag}^{+}$nonaqueous reference electrode with $0.001 \mathrm{M} \mathrm{AgNO} 3$ in $\mathrm{MeCN}$ (BASi Research Products), and a platinum wire counter electrode (Pine Research). The GC electrode was polished before every experiment using $0.05 \mu \mathrm{m}$ water-alumina slury (Allied High-tech Products Inc., DeAgglomerated) and polishing pad (Buehler). The reduction potential of ferrocene (Fc, Alfa Aesar, 99\%) was recorded before and after all electrochemical experiments to check the

consistency in the reference electrode. All potentials are reported versus the $\mathrm{Fc}^{+/ 0}$ couple and internal solution resistance was compensated for all experiments. CV experiments consisted of 
three continuous cycles starting at $-1.02 \mathrm{~V} \mathrm{vs} \mathrm{Fc}^{+/ 0}$ and scanning in a positive direction. Data from the third cycle was used for analysis. Pyridine (Sigma-Aldrich, anhydrous, 99.8\%), 4-tertbutylpyridine (Sigma-Aldrich, anhydrous, 96\%), 3-chloropyridine (Sigma-Aldrich, anhydrous, 99\%), 3-bromopyridine (Sigma-Aldrich, anhydrous, 99\%), 4-methylpyridine (Sigma-Aldrich, anhydrous, 99\%), 4-methoxypyridine (Sigma-Aldrich, anhydrous, 97\%), 4dimethylaminopyridine (Merck), quinoline (Sigma-Aldrich, 98\% ), 2-methylpyridine (Sigma, 98\%), 3-methanolpyridine (Sigma-Aldrich, anhydrous, 98\%), and 2,2'-bipyridine (Sigma-Aldrich, $99 \%$ ) were used as received and first purged with $\mathrm{N}_{2}$ prior to addition to electrolyte solutions.

Electrochemical Modeling DigiElch V8 was used to generate the working curve for rate constant analysis of the cyclic voltammetry data in presence of functionalized pyridines. Detailed information regarding the methods and parameters are provided in the supporting information.

Electron Paramagnetic Resonance (EPR) EPR samples were prepared by dissolving $1 \mathrm{mM}$ $\mathrm{Ni}^{\mathrm{II}}(\mathrm{dtc})_{2}$ and various amounts of 4-MeO-py in $\mathrm{MeCN}$ solvent and placing in an EPR tube. To this mixture, $1 \mathrm{mM}[\mathrm{AcF}] \mathrm{BF}_{4}$ in $\mathrm{DCM}$ as added and the solution was quickly frozen in liquid $\mathrm{N}_{2}$. Acetyl ferrocenium tetrafluoroborate $\left([\mathrm{AcFc}] \mathrm{BF}_{4}\right)$ was used as a chemical oxidant and synthesized following a published procedure. ${ }^{17,32}$ Briefly, silver tetrafluoroborate $\left(\mathrm{AgBF}_{4}\right.$, Sigma-Aldrich, 98\%) was added to a solution of acetyl ferrocene (AcFc, Alpha Aesar, 97\%) dissolved in diethyl ether under an inert atmosphere to generate a blue solid. This solid was then dissolved in dichloromethane (DCM, Macron, 99.9\%), filtered, and the filtrate evaporated to dryness to yield solid $[\mathrm{AcFc}] \mathrm{BF}_{4}$.

Continuous-wave EPR spectra were measured at the X-band (9 GHz) frequency on a Bruker EMX spectrometer fitted with an ER-4119-HS (high-sensitivity) perpendicular-mode cavity. All EPR spectra were collected at $77 \mathrm{~K}$ and performed by fitting the cavity with a liquid $\mathrm{N}_{2}$ cold finger Dewar. Spectra were recorded with a field modulation frequency of $100 \mathrm{kHz}$, a modulation amplitude of $6.00 \mathrm{G}$, and a microwave power of $1.995 \mathrm{~mW}$. The frequencies for the individual samples were slightly different but averaged $9.368 \mathrm{GHz}$. All simulations were modeled using hyperfine simulation software (W R Hagen Visual Software, V 1.0, 2009) ${ }^{33,34}$ with species having $\mathrm{S}=1 / 2$ electronic spin.

Density Functional Theory (DFT) Calculations Chemical structures were first modeled using Avogadro and then optimized using Gaussian ${ }^{35}$ with a $6-31+\mathrm{G}^{*}$ basis set, MN15 hybrid DFT functional, and a self-consistent reaction field using acetonitrile solvent. Optimizations were 
performed with the Alabama Supercomputer with convergence defined by the RMS Force, RMS Displacement, Max Force, and Max Displacement parameters. Calculation of g-values and superhyperfine coupling constants were performed using the TPSSh functional with EPR-II basis set (def2-TZVP) in ORCA using the Alabama Supercomputer. ${ }^{36,37,38}$

\section{Results and Discussion}

$\left[\boldsymbol{N i} i^{I I I}(\boldsymbol{d t c})_{2}(\boldsymbol{L})_{x}\right]^{+}$Formation $\mathrm{CV}$ studies were performed with $1 \mathrm{mM} \mathrm{Ni}{ }^{\mathrm{II}}(\mathrm{dtc})_{2}$ in $\mathrm{MeCN}$ with $0.1 \mathrm{M} \mathrm{TBAPF}_{6}$ electrolyte in the presence of derivatized pyridines. Figure 1 shows representative voltammograms for $\mathrm{Ni}^{\mathrm{II}}(\mathrm{dtc})_{2}$ collected at $1000 \mathrm{mV} \mathrm{s}^{-1}$ over a range of 0-383 mM [4-MeO-py] and [3-Br-py]. CV data for all ligands are shown in Figures S1-S10. Data for underivatized pyridine additions was recollected for this study and was quantitatively similar to previously published data. ${ }^{17}$ The addition of 4-MeO-py resulted in significant changes to the voltammogram with respect to the $0 \mathrm{mM}$ condition. The anodic peak was shifted in the negative direction and a new cathodic peak was produced which resulted in a quasi-reversible redox wave $\left(\Delta \mathrm{E}_{\mathrm{p}}=62 \mathrm{mV}\right.$ at 100 $\mathrm{mV} \mathrm{s}^{-1}$ for [4-MeO-py] $=383 \mathrm{mM}$ ). The addition of 3-Br-py resulted in similar behavior, however, with a smaller shift in the anodic peak and less reversibility in the new wave $\left(\Delta \mathrm{E}_{\mathrm{p}}=95 \mathrm{mV}\right.$ at 100 $\mathrm{mV} \mathrm{s}^{-1}$ for [3-Br-py] $=383 \mathrm{mM}$ ). The electrochemical behavior in both instances can be attributed to $1 \mathrm{e}^{-}$LCET where the oxidation of $\mathrm{Ni}^{-\mathrm{II}}(\mathrm{dtc})_{2}$ results in pyridine coordinated $\mathrm{Ni}\left(\mathrm{III}_{\mathrm{py}}\right)$ complexes to produce a new $\mathrm{Ni}\left(\mathrm{III}_{\mathrm{py}} / \mathrm{II}\right)$ redox wave (Equation 9). Table 1 shows a summary of electrochemical data collected for the series of pyridine-based ligands used in this study.
9) $\mathrm{Ni}^{\mathrm{II}}(\mathrm{dtc})_{2}+\mathrm{xL} \rightleftharpoons\left[\mathrm{Ni}^{\mathrm{III}}(\mathrm{dtc})_{2}(\mathrm{~L})_{\mathrm{x}}\right]^{+}+\mathrm{e}^{-}$
$E_{1 / 2}\left(\mathrm{III}_{\mathrm{py}} / \mathrm{II}\right)$ 

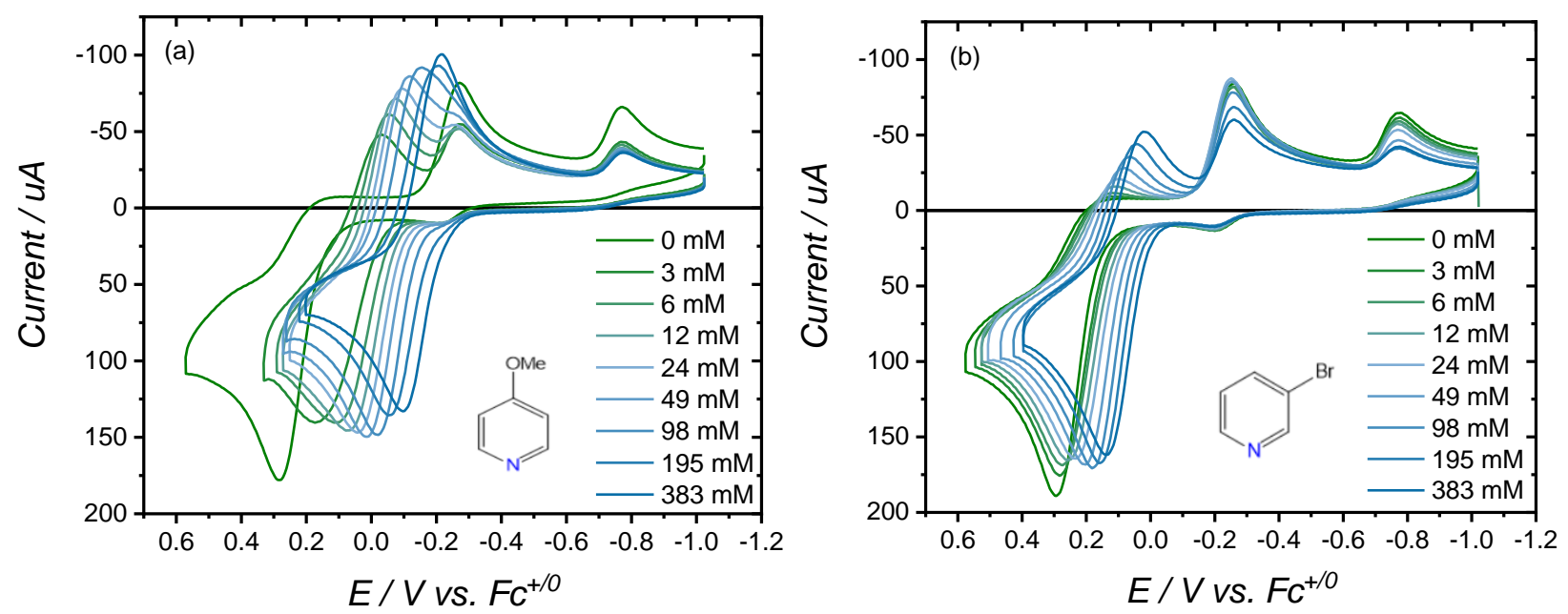

Figure 1. $\mathrm{CV}$ data for $1 \mathrm{mM} \mathrm{Ni}{ }^{\mathrm{II}}(\mathrm{dtc})_{2}$ with addition of (a) 4-MeO-py and (b) 3-Br-py over a concentration range of $0-383 \mathrm{mM}$. Both sets of data collected at $v=1000 \mathrm{mV} \mathrm{s}^{-1}$ in $\mathrm{MeCN}$ with $0.1 \mathrm{M} \mathrm{TBAPF}_{6}$ at room temperature.

Table 1. Summary of $E_{1 / 2}\left(\mathrm{III}_{\mathrm{py}} / \mathrm{II}\right)$ measured as a function of added pyridines $(\mathrm{L})^{\mathrm{a}}$

\begin{tabular}{cc|c|ccc}
\hline & & $\boldsymbol{E}_{1 / 2}$ & \multicolumn{3}{|c}{$\boldsymbol{E}_{\mathbf{1} / 2} \mathbf{~ v s ~} \mathbf{l o g}[\mathbf{L}]$} \\
$\mathbf{L}$ & $\mathbf{p K}_{\mathbf{a}}^{\mathbf{b}}$ & {$[\mathbf{L}]=\mathbf{4 9} \mathbf{~ m M}$} & $\mathbf{~ m V ~ d e c ~}^{\mathbf{- 1}}$ & $\mathbf{x}^{\mathbf{c}}$ & $\mathbf{K}_{\mathbf{e q}}{ }^{\mathbf{d}} / \mathbf{M}^{-\mathbf{x}}$ \\
\hline 4-N(CH$)_{2}$-py & 17.3 & -0.170 & 127 & 2.1 & $1.2 \times 10^{10}$ \\
4-MeO-py & 13.9 & -0.050 & 121 & 2.0 & $4.7 \times 10^{7}$ \\
4-tBu-py & 13.1 & 0.004 & 107 & 1.8 & $4.2 \times 10^{6}$ \\
4-Me-py & 13.1 & 0.007 & 96 & 1.6 & $2.2 \times 10^{6}$ \\
3-MeOH-py & 12.7 & 0.028 & 105 & 1.7 & $1.1 \times 10^{6}$ \\
pyridine (py) & 12.1 & 0.006 & 95 & 1.6 & $1.6 \times 10^{6}$ \\
3-Cl-py & 8.9 & 0.134 & 75 & 1.2 & $4.4 \times 10^{3}$ \\
3-Br-py & 8.9 & 0.144 & 67 & 1.1 & $2.1 \times 10^{3}$ \\
\hline
\end{tabular}

${ }^{\mathrm{a}}$ Data collected at $v=1000 \mathrm{mV} \mathrm{s}^{-1} ;{ }^{b}$ Values reported in $\mathrm{MeCN}^{39,40} ;{ }^{\mathrm{c}} \mathrm{x}=$ slope $/ 59 \mathrm{mV} \mathrm{dec}{ }^{-1}$; ${ }^{\mathrm{d}}$ Obtained from Equation 10 with $E^{o}=0.25 \mathrm{~V}$

Notably, the addition of quinoline or 2-Me-py did not show a significant shift in the anodic peak or appearance of a new cathodic peak with increased concentration of the ligand (Figure S9). This was attributed to steric hindrance from coordination to the nickel center due to ortho functionalization of the pyridine ring. The addition of 2,2'-bipyridine (bpy) was found to impact the electrochemistry of $\mathrm{Ni}^{\mathrm{II}}(\mathrm{dtc})_{2}$ (Figure S9); however, these results were not like those observed for monodendate pyridines and are believed to occur because of coordination of bpy to $\mathrm{Ni}^{\mathrm{II}}(\mathrm{dtc})_{2}$ prior to oxidation, thus producing new species such as $\mathrm{Ni}^{\mathrm{II}}(\mathrm{dtc})_{2}$ (bpy). The equilibrium constant for coordination of structurally similar 1,10-phenanthroline to form $\mathrm{Ni}^{\mathrm{II}}(\mathrm{dtc})_{2}(\mathrm{phen})$ has been 
measured in toluene to be $2240 \mathrm{M}^{-1}{ }^{41}$ By comparison, the equilibrium constant for coordination of pyridine to form $\mathrm{Ni}^{\mathrm{II}}(\mathrm{dtc})_{2}(\mathrm{py})_{2}$ has been measured to be much smaller, $0.087 \mathrm{M}^{-2}$ in $95 \%$ pyridine, $2.5 \% \mathrm{DCM}$, and 2.5\% tert-butyl alcohol. ${ }^{42}{ }^{1} \mathrm{H}-\mathrm{NMR}$ studies of $\mathrm{Ni}^{\mathrm{II}}(\mathrm{dtc})_{2}$ in the presence of each derivatized pyridine (10:1 excess pyridine) also showed no evidence for coordination of pyridines to the Ni(II) metal center (Figure S12-S19).

The observed $E_{1 / 2}\left(\mathrm{III}_{\mathrm{py}} / \mathrm{II}\right)$ for a given ligand concentration was found to increase with the $\mathrm{pK}_{\mathrm{a}}$ of the pyridine ligand. Likewise, plots of $E_{1 / 2}$ vs $\log [\mathrm{L}]$ (Figure 2) exhibited linear trends with slopes varying between $\sim 60$ and $\sim 120 \mathrm{mV} \mathrm{dec}^{-1}$ depending on the ligand. Based on Equation 10, the slope should be indicative of the number of coordinated ligands ( $\mathrm{x}$ ) and the intercept should be proportional to the equilibrium constant for ligand coordination $\left(\mathrm{K}_{\mathrm{eq}}\right)$. In this equation, $E^{o}$ refers to the standard reduction potential for the $\left[\mathrm{Ni}^{\mathrm{III}}\left(\mathrm{dtc}_{2}\right]^{+} / \mathrm{Ni}^{\mathrm{II}}(\mathrm{dtc})_{2}\right.$ redox couple measured in $\mathrm{MeCN}$ to be $0.25 \mathrm{~V} \mathrm{vs} \mathrm{Fc}^{+/ 0} \cdot{ }^{17}$ A slope of $120 \mathrm{mV} \mathrm{dec}{ }^{-1}$ would therefore indicate $\mathrm{x}=2$ with formation of a six-coordinate $\left[\mathrm{Ni}^{\mathrm{III}}(\mathrm{dtc})_{2}(\mathrm{~L})_{2}\right]^{+}$complex. A slope of $60 \mathrm{mV} \mathrm{dec}{ }^{-1}$ would indicate $\mathrm{x}=1$ and formation of a five-coordinate $\left[\mathrm{Ni}^{\mathrm{III}}(\mathrm{dtc})_{2}(\mathrm{~L})\right]^{+}$complex. Comparatively, these data show that ligands with a larger $\mathrm{pK}_{\mathrm{a}}$ yielded a larger slope while a smaller $\mathrm{pK}_{\mathrm{a}}$ resulted in a smaller slope.

$$
E_{1 / 2}\left(\mathrm{III}_{\mathrm{py}} / \mathrm{II}\right)=E^{o}(\mathrm{III} / \mathrm{II})-0.059 \log \mathrm{K}_{\mathrm{eq}}-0.059(\mathrm{x}) \log [\mathrm{L}]
$$

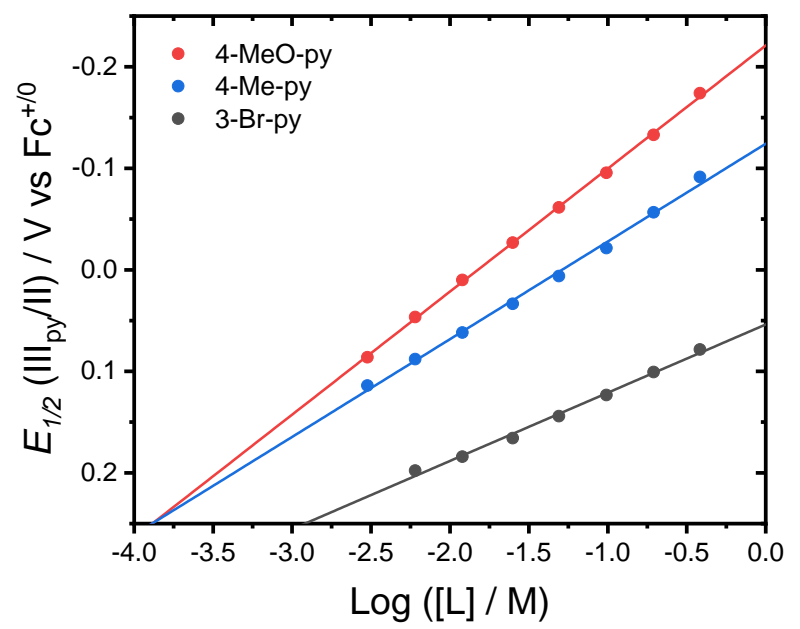

Figure 2. Plot of $E_{1 / 2}\left(\mathrm{III}_{\mathrm{py}} / \mathrm{II}\right)$ vs $\log [\mathrm{L}]$ for 4-MeO-py (red), 4-Me-py (blue), and 3-Br-py (black). Data measured at $1000 \mathrm{mV} \mathrm{s}^{-1}$. 
Observed slopes that fell between 60 and $120 \mathrm{mV} \mathrm{dec}^{-1}$ would appear to indicate a mixture of five- and six-coordinate $\mathrm{Ni}(\mathrm{III})$ species produced upon oxidation of $\mathrm{Ni}^{\mathrm{II}}(\mathrm{dtc})_{2}$. Reactions for the formation of each species are shown in Equations 11-12. This is a curious result and would imply that coordination and dissociation of the second ligand must occur on the timescale of the $\mathrm{CV}$ experiment in order to provide a mixture of $\mathrm{Ni}$ (III) complexes. Furthermore, this result suggests that the equilibrium constant for coordination of the second ligand is likely close to $1 \mathrm{M}^{-1}$ while that of the first ligand is much larger. In our previous study, we concluded that the addition of pyridine resulted in formation of only the six-coordinate complex. ${ }^{17}$ This was based on a parabolic fit to the $E_{1 / 2}$ vs [pyridine] data. Further analysis here comparing with other functionalized pyridines now shows that pyridine addition results in a $\sim 39 / 61$ mixture of five- and six-coordinate

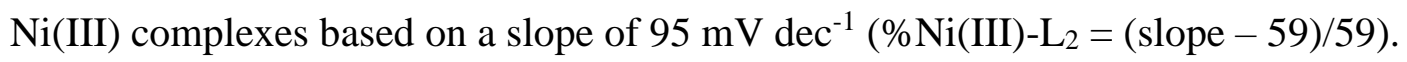

$$
\begin{array}{ll}
\text { 11) }\left[\mathrm{Ni}^{\mathrm{III}}(\mathrm{dtc})_{2}\right]^{+}+\mathrm{L} \rightleftharpoons\left[\mathrm{Ni}^{\mathrm{III}}(\mathrm{dtc})_{2}(\mathrm{~L})\right]^{+} & \mathrm{K}_{1 \text { py }} \\
\text { 12) } \left.\left[\mathrm{Ni}^{\mathrm{III}}(\mathrm{dtc})_{2}(\mathrm{~L})\right]^{+}+\mathrm{L} \rightleftharpoons \mathrm{Ni}^{\mathrm{III}}(\mathrm{dtc})_{2}(\mathrm{~L})_{2}\right]^{+} & \mathrm{K}_{2 \text { py }}
\end{array}
$$

Diagrams such as Figure 2 (i.e. Pourbaix diagrams) are often used to study PCET where the timescale for proton transfer is much faster than the $\mathrm{CV}$ experiment; fast enough to reach equilibrium and result in slopes proportional to integer values for the number of protons transferred in the reaction. ${ }^{43}$ In the present case, the occurrence of ligand coordination on the time scale of the $\mathrm{CV}$ experiment is also supported by the fact that $E_{1 / 2} \mathrm{vs} \log [\mathrm{L}]$ slopes were found to increase with larger scan rates (Figure S10). Beyond $1000 \mathrm{mV} \mathrm{s}^{-1}$, all slopes were found to level off to consistent values; however, slopes were found to decrease when the scan rate was decreased below $1000 \mathrm{mV}$ $\mathrm{s}^{-1}$. We believe this observation is an indication that the dissociation step for the second ligand is slower than the association step. High scan rates thus produce higher coordination numbers (i.e. larger slopes) whereas low scan rates allow time for equilibration through dissociation of the pyridine ligand.

The intercepts for the linear fits to data obtained at $1000 \mathrm{mV} \mathrm{s}^{-1}$ shown in Figure 2 were used to calculate $\mathrm{K}_{\mathrm{eq}}$ values for ligand association according to Equation 10 with $E^{o}=0.25 \mathrm{~V} .{ }^{17}$ Given the variable nature of coordination discussed above, the true meaning of these $\mathrm{K}_{\mathrm{eq}}$ values are difficult to interpret. In the extreme cases of $\mathrm{x}=2$ and $\mathrm{x}=1, \mathrm{~K}_{\mathrm{eq}}$ can be taken as the overall equilibrium constant for coordination of 2 ligands (i.e. $\mathrm{K}_{\mathrm{eq}}=\mathrm{K}_{1 \mathrm{py}} * \mathrm{~K}_{2 \mathrm{py}}$ ) with units of $\mathrm{M}^{-2}$ or the 
equilibrium constant for coordination of 1 ligand (i.e. $\mathrm{K}_{\mathrm{eq}}=\mathrm{K}_{1 \mathrm{py}}$ ) with units of $\mathrm{M}^{-1}$, respectively. Intermediate $\mathrm{x}$-values would result from a weighted average of equilibrium constants for each ligand proportional to the distribution of $\mathrm{Ni}(\mathrm{III})$ species. In this case, the overall $\mathrm{K}_{\mathrm{eq}}$ would possess units of $\mathrm{M}^{-\mathrm{x}}$. Nonetheless, a plot of $\log \left(\mathrm{K}_{\mathrm{eq}}\right) \mathrm{vs} \mathrm{pK}_{\mathrm{a}}$ of the ligand yields a strong correlation with $\mathrm{R}^{2}=0.98$ (Figure S11).

Isolation of pyridine coordination $\mathrm{Ni}$ (III) complexes was unsuccessful, however, formation of $\left[\mathrm{Ni}^{\mathrm{III}}(\mathrm{dtc})_{2}(\mathrm{~L})_{2}\right]^{+}$was confirmed by EPR spectroscopy. Figure 3 shows data collected with $1 \mathrm{mM}$ $\mathrm{Ni}^{\mathrm{II}}(\mathrm{dtc})_{2}, 1 \mathrm{mM} 4-\mathrm{MeO}-\mathrm{py}$, and $1 \mathrm{mM}\left[\mathrm{AcFc}_{\mathrm{BFF}}\right.$ as oxidant $E^{o}=0.26 \mathrm{~V} \mathrm{vs} \mathrm{Fc}^{+/ 0}$ ) in a 95:5 mixture of MeCN:DCM. The 4-MeO-py ligand was chosen based on its strong coordination ability to $\mathrm{Ni}(\mathrm{III})$ compared to other pyridines. Overall, the observed signal was complex and represented the presence of multiple $\mathrm{S}=1 / 2$ species. The values of $\mathrm{g}_{\mathrm{av}} \approx 2.10-2.14$ implies a metal-centered unpaired electron consistent with the $\mathrm{Ni}$ (III) $\mathrm{S}=1 / 2$ oxidation state. ${ }^{31,44}$ Simulation of the observed data according to the summation of two species could be achieved and is shown as the red dashed line overlaid on the experimental data. Individual components of this fit corresponding to each species are shown as offset dashed lines.

The first component (70\% total signal) is shown as the blue dashed line and represents a slightly rhombic spectrum with $\mathrm{g}_{123}=2.15,2.13,2.03$ and no superhyperfine coupling to $\mathrm{N}$ atoms present on the 4-MeO-py ligand. We assign this species to $\mathrm{Ni}^{\mathrm{III}}(\mathrm{dtc})_{3}$ formed via ligand exchange from pyridine bound $\mathrm{Ni}(\mathrm{III})$ complexes according to Equation 13. The second species (30\% total signal), shown as the green dashed line, is slightly rhombic with $\mathrm{g}_{123}=2.20,2.18,2.03$. This signal was simulated using superhyperfine coupling to two $\mathrm{N}$ atoms with coupling constants $\mathrm{A}_{123}=13.0$, 13.0, 18.0 G giving rise to quintet splitting with a $1: 2: 3: 2: 1$ intensity ratio. This superhyperfine pattern clearly indicates the coordination of two 4-MeO-py ligands to the $\mathrm{Ni}^{\mathrm{III}}$ center. ${ }^{45-49}$ Furthermore, the signal produced by the second species strongly resembles EPR data collected for trans-Ni ${ }^{\mathrm{III}}$ (salen)(py) $)_{2}$ complexes. ${ }^{44}$ The distinction between trans-(py $)_{2}$ and $c i s-(\mathrm{py})_{2}$ coordination is important in the present case as both are theoretically possible. The presence of a trans-(py) 2 signal in the EPR data also supports the quasireversible electrochemistry discussed above, where trans coordination would require minimal reorganization from the square planar $\mathrm{Ni}^{\mathrm{II}}(\mathrm{dtc})_{2}$ framework. 


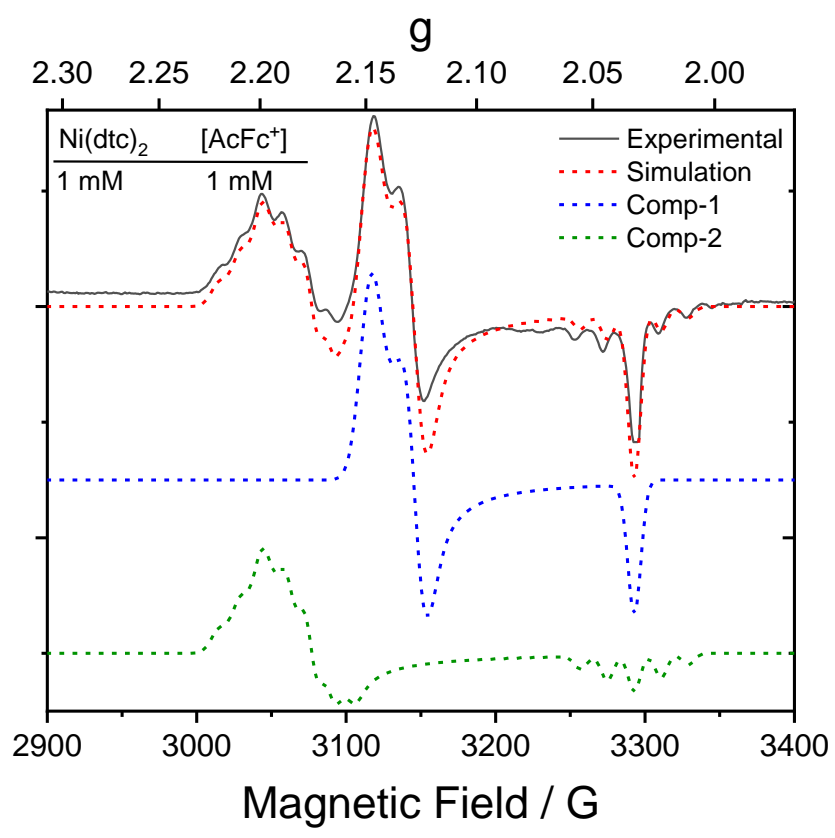

Figure 3. EPR spectra of $1 \mathrm{mM} \mathrm{Ni}^{\mathrm{II}}(\mathrm{dtc})_{2}$ in presence of $1 \mathrm{mM} 4-\mathrm{MeO}$-py and $1 \mathrm{mM}[\mathrm{AcFc}] \mathrm{BF}_{4}$ as oxidant. Black solid line is experimental data and red dashed line is a simulated spectrum for the summation of Comp-1 (70 \%) and Comp-2 (30\%) spectra. Blue dashed line is the simulated spectrum for Comp-1 (assigned to $\left[\mathrm{Ni}^{\mathrm{III}}(\mathrm{dtc})_{3}\right]$ ) using parameters $\mathrm{g}_{123}=2.15,2.13,2.03$. Green dash line is the simulated spectrum for Comp-2 (assigned to trans-[Ni $\left.\left.{ }^{\mathrm{III}}(\mathrm{dtc})_{2}(4-\mathrm{MeO}-\mathrm{py})_{2}\right]^{+}\right)$using parameters $g_{123}=2.20,2.18,2.03$ with superhyperfine coupling constants for two $\mathrm{N}$ atoms of $\mathrm{A}_{123}$ $=13.0,13.0,18.0 \mathrm{G}$.

13) $\left[\mathrm{Ni}^{\mathrm{III}}(\mathrm{dtc})_{2}(\mathrm{~L})_{\mathrm{x}}\right]^{+}+\mathrm{Ni}^{\mathrm{II}}(\mathrm{dtc})_{2} \rightarrow \mathrm{Ni}^{\mathrm{III}}(\mathrm{dtc})_{3}+\left[\mathrm{Ni}^{\mathrm{II}}(\mathrm{dtc})(\mathrm{L})_{\mathrm{x}}\right]^{+}$

Notably, the absence of 4-MeO-py resulted in an EPR silent species, presumably due to lowspin $\left[\mathrm{Ni}^{\mathrm{IV}}(\mathrm{dtc})_{3}\right]^{+}$formation as result of disproportionation following oxidation by $\mathrm{AcFc}^{+}$. At high [4-MeO-py], the signal was consistent with only Comp-1 being present and no evidence for superhyperfine coupling. We believe this is the result of the relatively slow timescale in which the EPR sample is prepared compared with the timescale of $\mathrm{CV}$ experiments. The time required to spike the $\mathrm{Ni}^{\mathrm{II}}(\mathrm{dtc})_{2} / 4-\mathrm{MeO}-$ py mixture with $[\mathrm{AcFc}] \mathrm{BF}_{4}$ and then quickly freeze the sample in liquid $\mathrm{N}_{2}$ is $\sim 40 \mathrm{~s}$ whereas the time required for the voltage to scan from $E_{p a}$ to $E_{p c}$ for the LCET redox wave ranged from $2 \mathrm{~s}$ for $39.81 \mathrm{mV} \mathrm{s}^{-1}$ to $0.2 \mathrm{~s}$ for $3981 \mathrm{mV} \mathrm{s}^{-1}$. Therefore, much of the $\left[\mathrm{Ni}^{\mathrm{III}}(\mathrm{dtc})_{2}(\mathrm{~L})_{2}\right]^{+}$species may have already decomposed to $\left[\mathrm{Ni}^{\mathrm{IV}}(\mathrm{dtc})_{3}\right]^{+}$by the time sample was 
frozen. Further supporting this theory is the integration of the total spin, which yielded $[\mathrm{Ni}(\mathrm{III})]=$ $0.25 \mathrm{mM}$, one-quarter of the expected [ $\mathrm{Ni}(\mathrm{III})]$ based on the 1:1 equivalent of chemical oxidant. Freeze-quench kinetic EPR experiments are currently being explored to provide further insight into the kinetics for $\mathrm{Ni}(\mathrm{III})$ disproportionation.

DFT calculations were performed to better understand and support experimental evidence for the formation of pyridine bound $\mathrm{Ni}$ (III) complexes. Calculations were carried out using basis set 6 $31+\mathrm{G}^{*}$ and MN15 hybrid DFT functional. For simplicity, only structures for underivatized pyridine were calculated. Figure 4 shows an energy level diagram summarizing the optimized structures and calculated total energies for $\left[\mathrm{Ni}^{\mathrm{III}}(\mathrm{dtc})_{2}\right]^{+},\left[\mathrm{Ni}^{\mathrm{III}}(\mathrm{dtc})_{2}(\mathrm{py})\right]^{+}, \operatorname{trans}-\left[\mathrm{Ni}^{\mathrm{III}}(\mathrm{dtc})_{2}(\mathrm{py})_{2}\right]^{+}$, cis-[ $\left[\mathrm{Ni}^{\mathrm{III}}(\mathrm{dtc})_{2}(\mathrm{py})_{2}\right]^{+}$, and analogous structures with $\mathrm{MeCN}$ coordination in place of pyridine. Spin density plots and selected molecular orbitals for all calculated complexes are shown in Figure S20-S27.

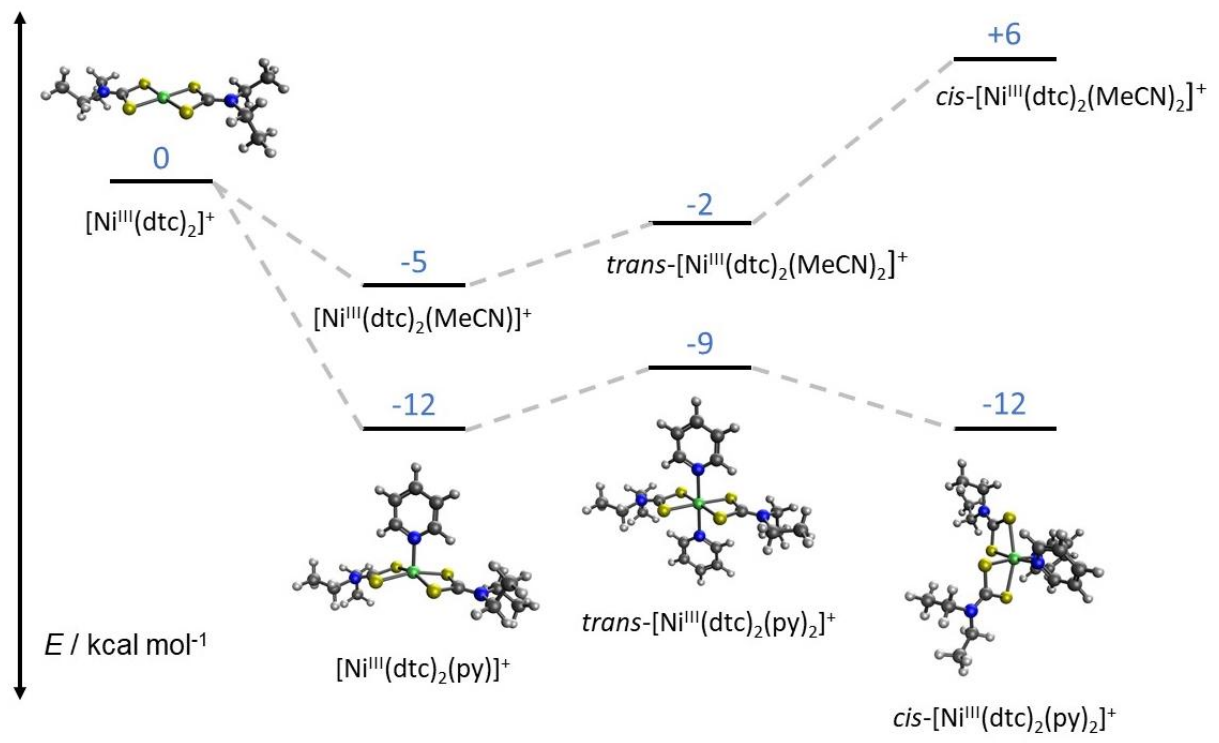

Figure 4. Energy level diagram which describes total energies for calculated pyridine and $\mathrm{MeCN}$ coordinated $\mathrm{Ni}(\mathrm{III})$ structures. Energies expressed relative to $\left[\mathrm{Ni}^{\mathrm{III}}(\mathrm{dtc})_{2}\right]^{+}$. Calculations were carried out using basis set 6-31+G* and MN15 hybrid DFT functional.

Formation of the five-coordinate $\left[\mathrm{Ni}^{\mathrm{III}}(\mathrm{dtc})_{2}(\mathrm{py})\right]^{+}$complex is shown to be $12 \mathrm{kcal} \mathrm{mol}^{-1}$ more favorable than the $\left[\mathrm{Ni}^{\mathrm{III}}(\mathrm{dtc})_{2}\right]^{+}$complex produced upon 1e $\mathrm{e}^{-}$oxidation of $\mathrm{Ni}^{\mathrm{II}}(\mathrm{dtc})_{2}$ and $7 \mathrm{kcal} \mathrm{mol}^{-}$ 1 more favorable than $\mathrm{MeCN}$ coordination. This is consistent with our experimental results 
showing large equilibrium constants for pyridine coordination in MeCN solvent. Interestingly, the equilibrium between five-coordinate $\left[\mathrm{Ni}^{\mathrm{III}}(\mathrm{dtc})_{2}(\mathrm{py})\right]^{+}$and six-coordinate complexes was calculated to be thermodynamically uphill in the case of trans-[Ni $\left.{ }^{\mathrm{III}}(\mathrm{dtc})_{2}(\mathrm{py})_{2}\right]^{+}\left(-9 \mathrm{kcal} \mathrm{mol}^{-1}\right)$ and isoenergetic in the case of $c i s-\left[\mathrm{Ni}^{\mathrm{III}}(\mathrm{dtc})_{2}(\mathrm{py})_{2}\right]^{+}\left(-12 \mathrm{kcal} \mathrm{mol}^{-1}\right)$. A similar trend was found for $\mathrm{MeCN}$ coordination where the trans $-(\mathrm{MeCN})_{2}$ structure was uphill with respect to $\left[\mathrm{Ni}^{\mathrm{III}}(\mathrm{dtc})_{2}(\mathrm{MeCN})\right]^{+}$, however, the cis- $(\mathrm{MeCN})_{2}$ was found to be thermodynamically unfavorable with respect to all $\mathrm{Ni}(\mathrm{III})$ complexes. These results support our experimental findings as they indicate that the five- and six-coordinate complexes are close in energy and therefore could produce a mixture of products upon $1 \mathrm{e}^{-}$oxidation.

Table 2. Summary of experimental and theoretical EPR data for Ni(III) complexes

\begin{tabular}{|c|c|c|c|c|c|c|c|}
\hline Experimental Data & $\mathbf{g}_{1}$ & $\mathbf{g}_{2}$ & $\mathbf{g}_{3}$ & $\left(g_{1}+g_{2}\right) / 2$ & $\mathbf{A}_{1}{ }^{c}$ & $\mathbf{A}_{3}{ }^{\mathbf{c}}$ & $\mathbf{A}_{3}{ }^{c}$ \\
\hline Comp-1 ${ }^{\mathrm{a}}$ & 2.15 & 2.13 & 2.03 & 2.14 & 0 & 0 & 0 \\
\hline Comp- $2^{\mathrm{b}}$ & 2.20 & 2.18 & 2.03 & 2.19 & 13.0 & 13.0 & 18.0 \\
\hline Calculated Data $^{\mathrm{d}}$ & $\mathbf{g}_{1}$ & $\mathbf{g}_{2}$ & $\mathbf{g}_{3}$ & $\left(g_{1}+g_{2}\right) / 2$ & $\mathbf{A}_{1}{ }^{c}$ & $\mathbf{A}_{3}{ }^{\mathbf{c}}$ & $\mathbf{A}_{3}{ }^{\mathbf{c}}$ \\
\hline$\left[\mathrm{Ni}^{\mathrm{III}}(\mathrm{dtc})_{2}\right]^{+}$ & 2.21 & 2.19 & 2.03 & 2.20 & 0 & 0 & 0 \\
\hline$\left[\mathrm{Ni}^{\mathrm{iII}}(\mathrm{dtc})_{2}(\mathrm{py})\right]^{+}$ & 2.16 & 2.14 & 2.03 & 2.15 & 15.2 & 16.1 & 21.8 \\
\hline trans $-\left[\mathrm{Ni}^{\mathrm{III}}(\mathrm{dtc})_{2}(\mathrm{py})_{2}\right]^{+}$ & 2.13 & 2.11 & 2.03 & 2.12 & 14.4 & 14.6 & 19.7 \\
\hline$c i s-\left[\mathrm{Ni}^{\mathrm{III}}(\mathrm{dtc})_{2}(\mathrm{py})_{2}\right]^{+}$ & 2.07 & 2.07 & 2.03 & 2.07 & 0 & 0 & 0 \\
\hline $\mathrm{Ni}^{\mathrm{III}}(\mathrm{dtc})_{3}$ & 2.09 & 2.07 & 2.03 & 2.08 & 0 & 0 & 0 \\
\hline
\end{tabular}

${ }^{\mathrm{a}}$ Assigned to $\mathrm{Ni}^{\mathrm{III}}(\mathrm{dtc})_{3}$; ${ }^{\mathrm{b}}$ Assigned to trans-[Ni $\left.{ }^{\mathrm{III}}(\mathrm{dtc})_{2}(\mathrm{py})_{2}\right]^{+} ;{ }^{\mathrm{c}}$ Coupling constants expressed in Gauss; ${ }^{\mathrm{d}}$ Calculations performed with TPSSh functional with EPR-II basis set (def2-TZVP) in ORCA

DFT calculations were also used to generate theoretical g-values and nitrogen coupling constants for comparison with experimental EPR results (Table 2). Theoretical values for trans$\left[\mathrm{Ni}^{\mathrm{III}}(\mathrm{dtc})_{2}(\mathrm{py})_{2}\right]^{+}(\mathrm{Comp}-2)$ predicted a slightly rhombic spectrum with $\mathrm{g}_{123}=2.13,2.11,2.03$ and coupling constants of $\mathrm{A}_{123}=14.4,14.6,19.7$. These values were in close agreement with the experimental values for Comp-2 of $\mathrm{g}_{123}=2.20,2.18,2.03$ and $\mathrm{A}_{123}=13.0,13.0,18.0$, albeit with slightly smaller $g_{1}$ and $g_{2}$ compared with experiment. This reduction in $g_{1}$ and $g_{2}$ appeared to be systematic across all calculations as the calculated values for $\mathrm{Ni}^{\mathrm{III}}(\mathrm{dtc})_{3}$ were $\mathrm{g}_{123}=2.09,2.07$, 2.03 compared with $\mathrm{g}_{123}=2.15,2.13,2.03$ obtained from experiment for Comp-1. Nonetheless, 
DFT calculations consistently revealed larger $\mathrm{g}_{1}$ and $\mathrm{g}_{2}$ values for molecules with a trans-(dtc) $)_{2}$ ligand framework $\left(\left(\mathrm{g}_{1}+\mathrm{g}_{2}\right) / 2>2.12\right)$ compared with a cis- $(\mathrm{dtc})_{2}$ framework $\left(\left(\mathrm{g}_{1}+\mathrm{g}_{2}\right) / 2 \sim 2.07\right)$. Given this trend, we note that assignment of Comp-1 as $c i s-\left[\mathrm{Ni}^{\mathrm{III}}(\mathrm{dtc})_{2}(\mathrm{py})_{2}\right]^{+}$is also possible as this coordination environment is not predicted to result in superhyperfine coupling to the $\mathrm{N}$ atoms and the predicted g-values are nearly identical with that of $\mathrm{Ni}^{\mathrm{III}}(\mathrm{dtc})_{3}$. However, based on the overall mechanism for ligand exchange of pyridine bound $\mathrm{Ni}(\mathrm{III})$ complexes to form $\mathrm{Ni}^{\mathrm{III}}(\mathrm{dtc})_{3}$ discussed below, we believe Comp-1 is more accurately assigned to $\mathrm{Ni}^{\mathrm{III}}(\mathrm{dtc})_{3}$.

$\left[\mathrm{Ni}^{\mathrm{III}}(\boldsymbol{d t c})_{2}(\boldsymbol{L})_{x}\right]^{+}$Decomposition The reversibility of the LCET Ni(III $\left.\mathrm{py}_{\mathrm{py}} / \mathrm{II}\right)$ redox wave was found to be dependent on scan rate for every pyridine tested. High scan rates produced more a reversible wave while low scan rates resulted in irreversibility. A comparison of CV data collected for 4-MeO-py and 3-Br-py, each with $[\mathrm{L}]=383 \mathrm{mM}$, as a function of scan rate is shown in Figure 5 to illustrate these observations. Scan rate dependent data for all other ligands can be found in Figure S1-S8. Data are normalized by dividing current by (scan rate) ${ }^{1 / 2}$ to highlight changes as a function of scan rate without an increase in current due to diffusion. The data for 4-MeO-py shows that the cathodic current for the ligand coupled redox wave at $E_{1 / 2}=-0.16 \mathrm{~V}$ slowly decreases in magnitude as the scan rate is decreased. In the case of 3-Br-py, the ligand coupled cathodic peak $\left(E_{1 / 2}=0.08 \mathrm{~V}\right)$ also decreases with lower scan rate, however, an increase in peak currents associated with $\left[\mathrm{Ni}^{\mathrm{IV}}(\mathrm{dtc})_{3}\right]^{+} \rightarrow \mathrm{Ni}^{\mathrm{III}}(\mathrm{dtc})_{3}\left(E_{p c} \sim-0.25 \mathrm{~V}\right)$ and $\mathrm{Ni}^{\mathrm{III}}(\mathrm{dtc})_{3} \rightarrow \mathrm{Ni}^{\mathrm{II}}(\mathrm{dtc})_{2}$ reduction $\left(E_{p c} \sim-0.75 \mathrm{~V}\right)$ were also observed at lower scan rates. We believe similar changes in peak currents occurred in the case of 4-MeO-py, however, the proximity of the two reduction peaks made this observation less clear. 

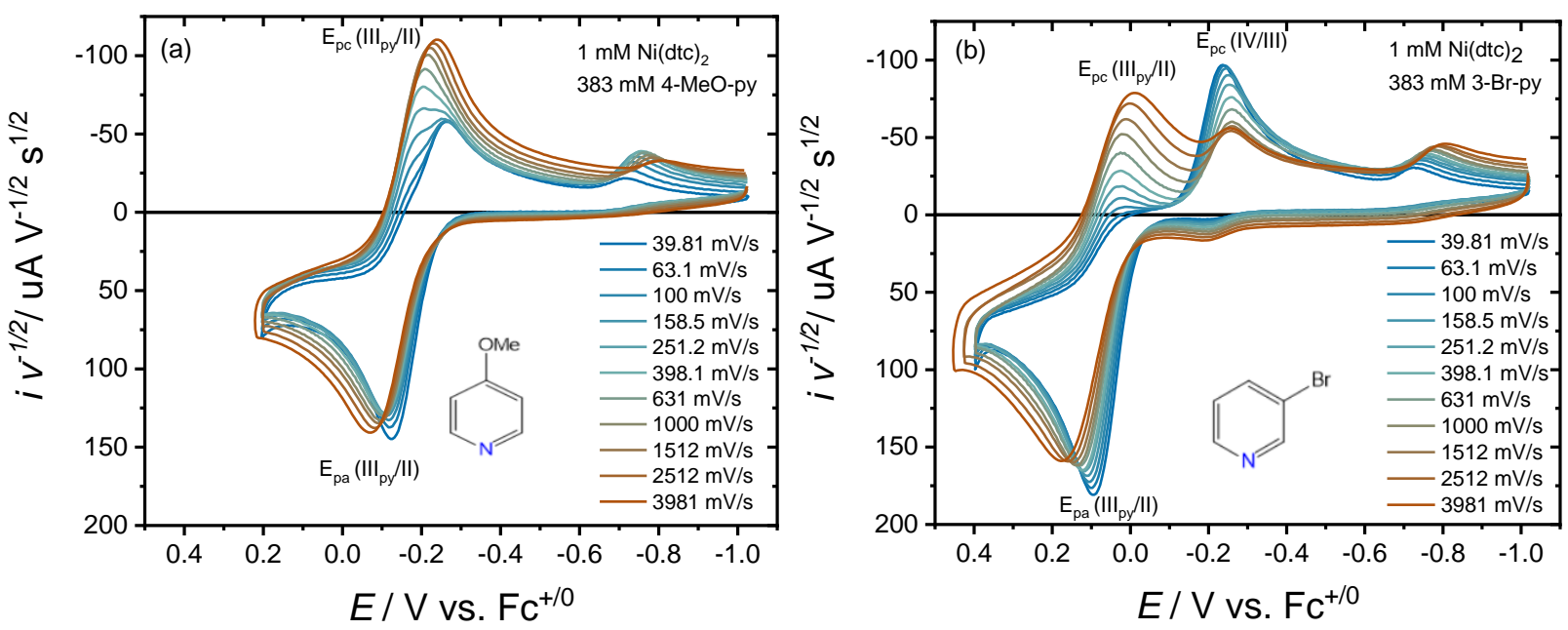

Figure 5. $\mathrm{CV}$ data normalized by (scan rate) $)^{-1 / 2}$ for $1 \mathrm{mM} \mathrm{Ni}(\mathrm{dtc})_{2}$ with the addition of $383 \mathrm{mM}$ a) 4-MeO-py and b) 3-Br-py as a function of scan rate. Both sets of data collected in MeCN with $0.1 \mathrm{M} \mathrm{TBAPF}_{6}$.

This type of scan rate dependent behavior was previously reported by our group for pyridine addition and can be described by Scheme $2 .{ }^{17}$ At high scan rates, the $\left[\mathrm{Ni}^{\mathrm{III}}(\mathrm{dtc})_{2}(\mathrm{~L})_{\mathrm{x}}\right]^{+}$species produced upon oxidation are reduced back to dissociated $\mathrm{Ni}^{\mathrm{II}}(\mathrm{dtc})_{2}$ and $\mathrm{xL}$, resulting in a quasireversible redox wave. However, at low scan rates, an irreversible decomposition of $\left[\mathrm{Ni}^{\mathrm{III}}(\mathrm{dtc})_{2}(\mathrm{~L})_{\mathrm{x}}\right]^{+}$occurs to ultimately produce $\left[\mathrm{Ni}^{\mathrm{IV}}(\mathrm{dtc})_{3}\right]^{+}$. The kinetics for this irreversible decomposition can be studied by plotting the peak current ratios for the ligand coupled redox wave $\left(-\mathrm{i}_{\mathrm{pc}} / \mathrm{i}_{\mathrm{pa}}\right)$ as a function of scan rate. Figure 6a shows comparative data for 3-Br-py, 4-Me-py, and 4-MeO-py at the same concentration of $[\mathrm{L}]=98 \mathrm{mM}$. Here, we can see that for each ligand studied, the $-\mathrm{i}_{\mathrm{pc}} / \mathrm{i}_{\mathrm{pa}}$ ratio increased toward high scan rates, indicating greater reversibility, and decreased at low scan rates, indicating irreversible decomposition. Note also that peak currents $i_{p c}$ and $i_{p a}$ were obtained directly from CV data without correcting for non-faradaic background current. This method removes any errors that may occur during background subtraction but results in a maximum $-i_{\mathrm{pc}} / \mathrm{i}_{\mathrm{pa}} \sim 0.7$ instead of the ideal $-\mathrm{i}_{\mathrm{pc}} / \mathrm{i}_{\mathrm{pa}}=1$. Overall, data points which reflect higher current ratios at lower scan rates is an indication of higher stability in the pyridine bound $\mathrm{Ni}$ (III) complexes. This stability was thus found to be dependent on the nature of the coordinating pyridine. Ligands with larger $\mathrm{pK}_{\mathrm{a}}$ 's such as 4-MeO-py were more stable while those with smaller $\mathrm{pK}_{\mathrm{a}}$ 's such as 3-Br-py required higher scan rates to achieve modest levels of reversibility due to rapid decomposition on the $\mathrm{CV}$ timescale. 


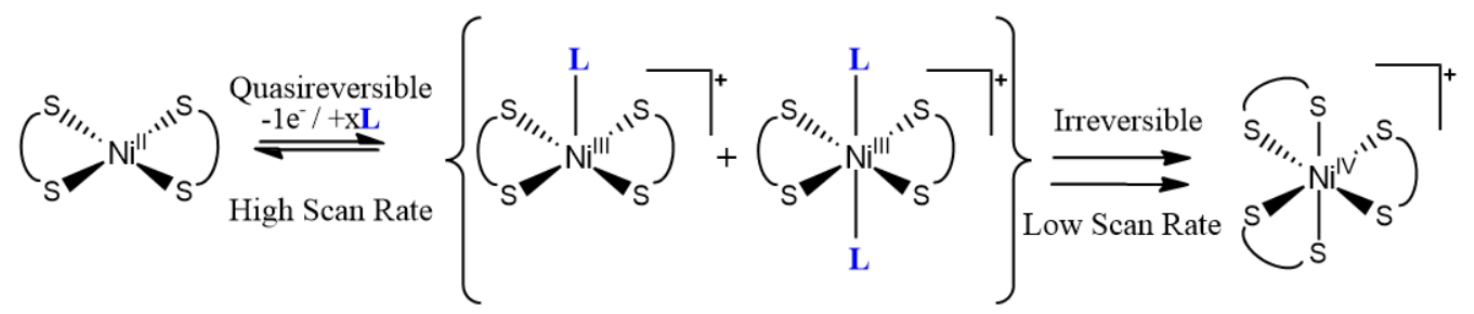

Scheme 2. Proposed reaction mechanism for formation and decay of $\left[\mathrm{Ni}^{\mathrm{III}}(\mathrm{dtc})_{2}(\mathrm{~L})_{\mathrm{x}}\right]^{+}$complexes as a function of scan rate.
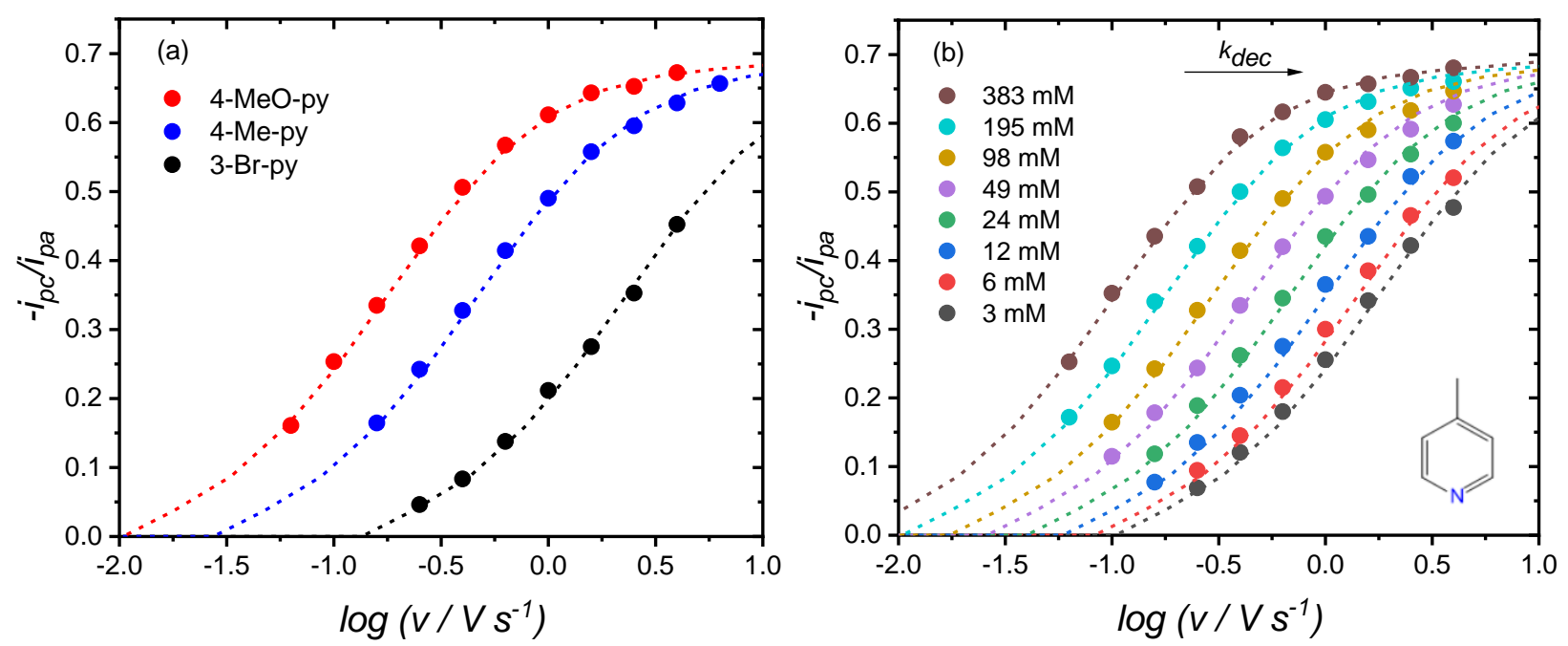

Figure 6. Cathodic-to-anodic peak current ratios $\left(-i_{p c} / i_{p a}\right)$ plotted versus $\log (v)(v=$ scan rate) for addition of a) 3-Br-py, 4-Me-py, and 4-MeO-py at the same concentration of $98 \mathrm{mM}$ and b) 4-Mepy as a function of [L]. In both plots, dashed lines are simulations generated for an ECE/DISP1 mechanism and used to determine the rate constant for decomposition of $\left[\mathrm{Ni}^{\mathrm{III}}(\mathrm{dtc})_{2}(\mathrm{~L})_{\mathrm{x}}\right]^{+}$.

Another key observation from these studies is shown in Figure $6 \mathbf{b}$ for the case of 4-Me-py. Here, the $-\mathrm{i}_{\mathrm{pc}} / \mathrm{i}_{\mathrm{pa}}$ ratio as a function of $\log (\mathrm{v})$ is shown to increase with higher concentrations of [L]. For example, at a given scan rate of $1000 \mathrm{mV} \mathrm{s}^{-1},-\mathrm{i}_{\mathrm{pc}} / \mathrm{i}_{\mathrm{pa}}$ increased from 0.26 to 0.65 when going from 3 to $383 \mathrm{mM}$ 4-Me-py. This observation was general for all ligands studied (Figure S1-S8) and indicates that the pyridine bound $\mathrm{Ni}(\mathrm{III})$ complexes became more stable as more ligand was added to solution.

The peak current ratio data was fit as a function of scan rate based on a working curve generated from an ECE-DISP1 mechanism to extract a decomposition rate constant $k_{d e c}$ (see Supporting 
Information for full details). ${ }^{17}$ Simulations of the $-\mathrm{i}_{\mathrm{pc}} / \mathrm{i}_{\mathrm{pa}}$ data are shown in Figure 6 as overlaid dashed lines and show good agreement with the measured data. Table 3 shows a condensed summary of $k_{d e c}$ values for each ligand at $3 \mathrm{mM}$ and $383 \mathrm{mM}$ to highlight the decrease in $k_{d e c}$ with increased [L] for all ligands studied. A complete summary of $k_{d e c}$ values for all concentrations can be found in Table S1.

Table 3. Summary of rate constants for $\left[\mathrm{Ni}^{\mathrm{III}}(\mathrm{dtc})_{2}(\mathrm{~L})_{\mathrm{x}}\right]^{+}$decomposition ${ }^{\mathrm{a}}$

\begin{tabular}{|c|c|c|c|c|c|c|}
\hline $\mathbf{L}$ & $\begin{array}{l}k_{d e c} \mathrm{~s}^{-1} \\
\mathbf{3} \mathbf{~ m M}\end{array}$ & $\begin{array}{c}k_{\text {dec }} \mathrm{s}^{-1} \\
383 \mathrm{mM}\end{array}$ & $k_{1}^{\prime} / \mathrm{M} \mathrm{s}^{-1}$ & $k_{2} / \mathrm{s}^{-1}$ & $k_{-L} / \mathrm{s}^{-1}$ & $\sigma^{b}$ \\
\hline $4-\mathrm{N}\left(\mathrm{CH}_{3}\right)_{2}-\mathrm{py}$ & 2.0 & 0.1 & $0.021(5)$ & $0.05(14)$ & $2.8(2)$ & -0.83 \\
\hline 4-MeO-py & 3.7 & 0.3 & $0.021(2)$ & $0.35(6)$ & $6.3(7)$ & -0.27 \\
\hline 4-tBu-py & 8.0 & 0.3 & $0.067(4)$ & $0.28(8)$ & $11.7(4)$ & -0.20 \\
\hline 4-Me-py & 6.0 & 0.4 & $0.065(4)$ & $0.29(6)$ & $7.7(2)$ & -0.17 \\
\hline 3-MeOH-py & 10.5 & 0.4 & $0.117(9)$ & $0.10(3)$ & $16(3)$ & 0.00 \\
\hline pyridine (py) & 9.0 & 0.7 & $0.044(3)$ & $0.80(6)$ & $10.6(6)$ & 0.00 \\
\hline 3-Br-py & 32.0 & 3.7 & $0.22(4)$ & $4.8(8)$ & $42(5)$ & 0.39 \\
\hline 3-Cl-py & 35.0 & 2.5 & $0.25(4)$ & $2.8(7)$ & $51(5)$ & 0.37 \\
\hline
\end{tabular}

The ECE-DISP1 mechanism specifically implies that the overall decomposition of $\left[\mathrm{Ni}^{\mathrm{III}}(\mathrm{dtc})_{2}(\mathrm{~L})_{\mathrm{x}}\right]^{+}$into $\left[\mathrm{Ni}^{\mathrm{IV}}(\mathrm{dtc})_{3}\right]^{+}$occurs by disproportionation according to Equation 14, but is rate limited by the ligand exchange step required to produce $\mathrm{Ni}^{\mathrm{III}}(\mathrm{dtc})_{3}$ (Equation 13). These reaction steps are akin to disproportionation (Equation 5) and ligand exchange (Equation 3) used to describe the overall oxidation of $\mathrm{Ni}^{\mathrm{II}}(\mathrm{dtc})_{2}$ to $\left[\mathrm{Ni}^{\mathrm{IV}}(\mathrm{dtc})_{3}\right]^{+}$in the absence of pyridine-based ligands. Within the DISP1 mechanism, $k_{d e c}$ can be taken as a pseudo-first order rate constant for Equation 13 with $\left[\mathrm{Ni}^{\mathrm{II}}(\mathrm{dtc})_{2}\right]=1 \mathrm{mM}$. By comparison, the pseudo-first order rate constant for the ligand exchange step in $\mathrm{MeCN}\left(\left[\mathrm{Ni}^{\mathrm{II}}(\mathrm{dtc})_{2}\right]=1 \mathrm{mM}\right)$ without added pyridine ligands has been measured to be $34 \mathrm{~s}^{-1} \cdot{ }^{17}$ The decrease in rate constants in the presence of pyridine-based ligands highlights the ability of pyridine coordination to trap the $\mathrm{Ni}$ (III) oxidation state by inhibiting the overall ligand exchange step to yield $\mathrm{Ni}^{\mathrm{III}}(\mathrm{dtc})_{3}$.

14) $\left[\mathrm{Ni}^{\mathrm{III}}(\mathrm{dtc})_{2}(\mathrm{~L})_{\mathrm{x}}\right]^{+}+\mathrm{Ni}^{\mathrm{III}}(\mathrm{dtc})_{3} \rightarrow \mathrm{Ni}^{\mathrm{II}}(\mathrm{dtc})_{2}+\mathrm{xL}+\left[\mathrm{Ni}^{\mathrm{IV}}(\mathrm{dtc})_{3}\right]^{+}$ 
Upon inspection of $k_{d e c}$ as a function of both ligand and concentration, we can see that ligands with a larger $\mathrm{pK}_{\mathrm{a}}$ tend to display smaller $k_{d e c}$ and those with a smaller $\mathrm{pK}_{\mathrm{a}}$ result in larger $k_{d e c}$. The decrease in $k_{d e c}$ with higher [L] has been explained previously by our group using a parallel decomposition mechanism in which $\left[\mathrm{Ni}^{\mathrm{III}}(\mathrm{dtc})_{2}(\mathrm{~L})\right]^{+}$and $\left[\mathrm{Ni}^{\mathrm{III}}(\mathrm{dtc})_{2}(\mathrm{~L})_{2}\right]^{+}$undergo rate limited ligand exchange and disproportionation independently to yield $\left[\mathrm{Ni}^{\mathrm{IV}}(\mathrm{dtc})_{3}\right]^{+}$with an $[\mathrm{L}]$ dependent equilibrium between the two species, Scheme $3 .{ }^{17}$ The equilibrium between $\left[\mathrm{Ni}^{\mathrm{III}}(\mathrm{dtc})_{2}(\mathrm{~L})\right]^{+}$and $\left[\mathrm{Ni}^{\mathrm{III}}(\mathrm{dtc})_{2}(\mathrm{~L})_{2}\right]^{+}$described by $\mathrm{K}_{\mathrm{L}}=k_{L} / k_{-L}$ is critical to this mechanism as it allows for an inverse dependence of $k_{d e c}$ on [L]. Accordingly, $k_{d e c}$ can be described by Equation 15 where $k_{1}$ and $k_{2}$ are the decomposition rate constants for $\left[\mathrm{Ni}^{\mathrm{III}}(\mathrm{dtc})_{2}(\mathrm{~L})\right]^{+}$and $\left[\mathrm{Ni}^{\mathrm{III}}(\mathrm{dtc})_{2}(\mathrm{~L})_{2}\right]^{+}$, respectively. Figure 7 shows a plot of $k_{d e c}$ vs [L] for a selection of pyridine-based ligands with overlaid lines fit to Equation 15. Similar plots and fits for all ligands are shown in Figure S1-S8.

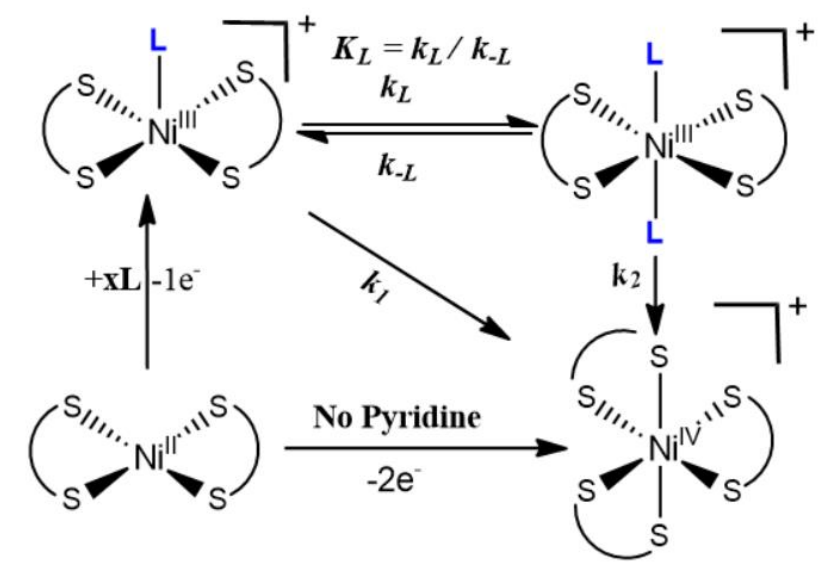

Scheme 3. Intermediate parallel decomposition mechanism pathways.

$$
k_{d e c}=k_{2}+\frac{k_{1}^{\prime} k_{-L}}{k_{1}^{\prime}+k_{-L}[L]} \quad k_{1}^{\prime}=k_{1} / K_{L}
$$




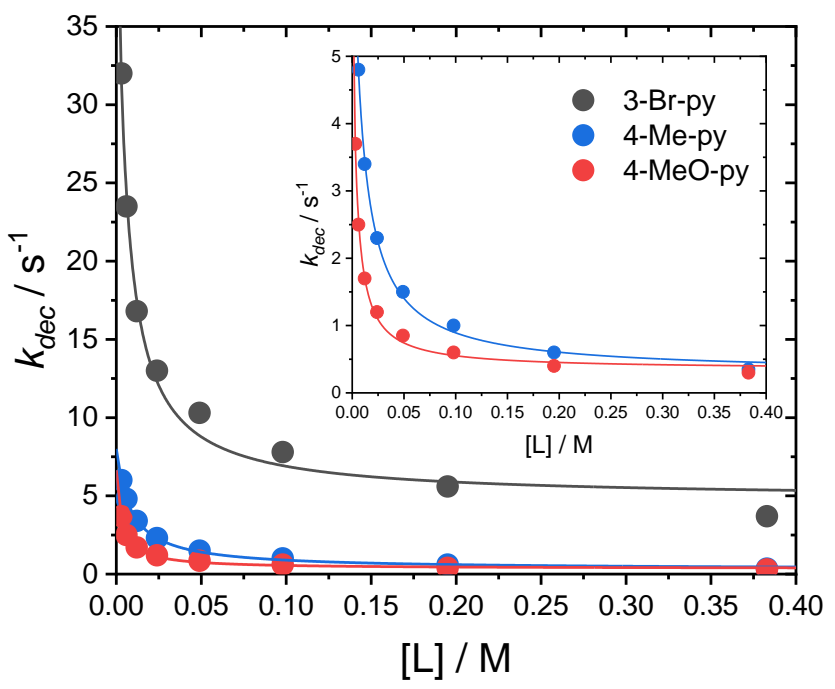

Figure 7. Comparison of $k_{d e c}$ as a function of [L] for 3-Br-py, 4-Me-py, and 4-MeO-py. The solid overlaid lines represent fits to Equation 15. Inset shows the region of small $k_{d e c}$ to highlight fits for 4-Me-py and 4-MeO-py.

Rate constants $k_{l}$ ', $k_{2}$, and $k_{-L}$ extracted from fits to Equation 15 are presented in Table 3. In general, all rate constants were found to increase for ligands with a smaller $\mathrm{pK}_{\mathrm{a}}$, consistent with the observation that these ligands produced a less reversible $\mathrm{Ni}\left(\mathrm{III}_{\mathrm{py}} / \mathrm{II}\right)$ redox wave. In the case of $k_{-L}$, the lifetime of $\left[\mathrm{Ni}^{\mathrm{iII}}(\mathrm{dtc})_{2}(\mathrm{~L})_{2}\right]^{+}$can be estimated by $1 / k_{-L}$ to be in the range of $30-300 \mathrm{~ms}$ for all ligands. These lifetimes are on the timescale of the $\mathrm{CV}$ experiments $(\mathrm{ms}-\mathrm{s}$; depending on scan rate) and further support the observation of variable ligand coordination as a function of scan rate and ligand identity. Assuming an equilibrium constant for $\mathrm{K}_{\mathrm{L}}$ in the range of 1-100 $\mathrm{M}^{-1}, k_{l}$ can be estimated to be 1-2 orders of magnitude larger than $k_{l}$ '.

Hammett plots are shown in Figure 8 for each rate constant where strong correlation was found for $k_{-L}\left(\mathrm{R}^{2}=0.92\right)$ and $k_{2}\left(\mathrm{R}^{2}=0.97\right)$ with respect to the electronic character of the pyridine ligand, producing larger rate constants for more electron-withdrawing pyridines. This indicates that the dissociation of pyridine is likely the rate limiting step for these reactions. This is an expected result in the case of $k_{-L}$ as the reaction is described directly as ligand dissociation. However, $k_{2}$ is more complex and involves loss of pyridine along with coordination of an additional dtc ${ }^{-}$ligand through ligand exchange. The fitting analysis for $k_{2}$ also ignores the data point for 3-MeOH-py, shown as the hollow data point. The Hammett parameter for this ligand was assumed to be equal to 3-Mepy, which yields an anomalously low value for $k_{2}$ compared with other pyridines. This may be the 
result of the alcohol group playing a role during ligand exchange which breaks from the observed trend for other pyridines. Figure $\mathbf{S 2 8}$ shows a linear fit which includes this data point for reference. The correlation for $k_{1}$ ' with the Hammett parameter was found to be the weakest $\left(\mathrm{R}^{2}=0.77\right)$. This result is unsurprising given that $k_{l}$ ' also involves ligand exchange and factors in the equilibrium constant for pyridine coordination. This high combination of terms may make it difficult to find strong correlation with $k_{1}$ '.
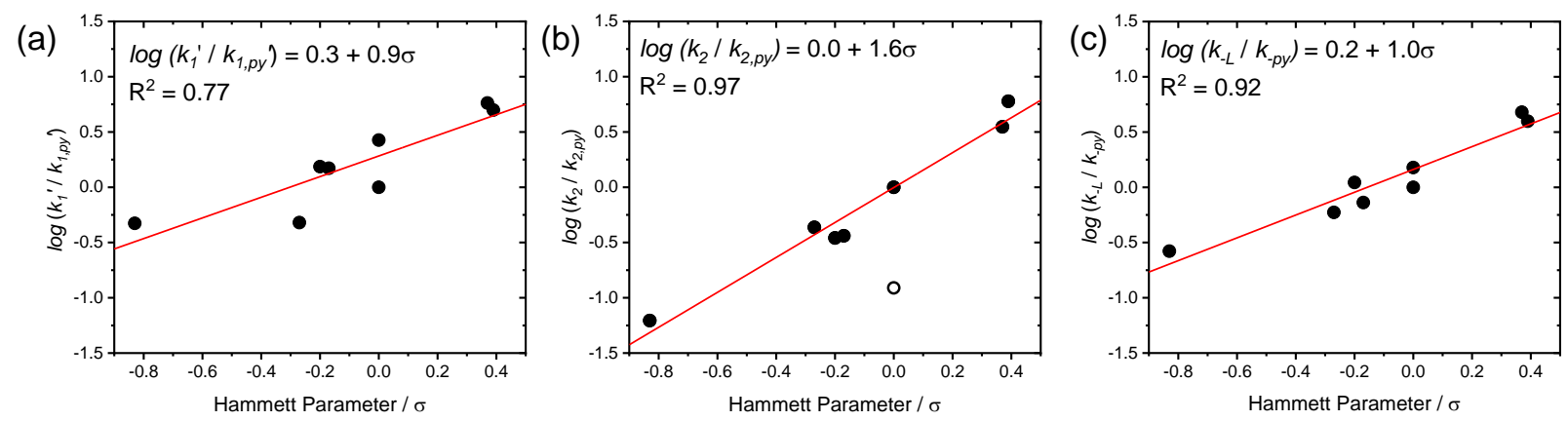

Figure 8. (a-c) Hammett plots for rate constants $k_{1}$ ', $k_{2}$, and $k_{-L}$ determined by fitting $k_{d e c}$ vs [L] using Equation 15. $k_{l, p y}$ ', $k_{2, p y}$, and $k_{-p y}$ refer to rate constants determined for underivatized pyridine.

The details of the ligand exchange step are unknown but the mechanism is anticipated to proceed through dithiocarbamate bridged dimers between $\{\mathrm{Ni}(\mathrm{III}), \mathrm{Ni}(\mathrm{II})\}$ metal centers. Notably, dithiocarbamate dimers of $\{\mathrm{Co}(\mathrm{III}), \mathrm{Co}(\mathrm{III})\}$ and $\{\mathrm{Ru}(\mathrm{III}), \mathrm{Ru}(\mathrm{III})\}$ metal centers have been structurally characterized in the literature. In the present case, the addition of pyridine does not appear to stabilize any dimer formation as the only $\mathrm{Ni}(\mathrm{III})$ complexes which are detectable by $\mathrm{CV}$ or EPR are monomeric. This implies that dimers are short lived and ligand exchange occurs quickly once initiated. This point reinforces the general observation here that pyridine is able to kinetically trap the $\mathrm{Ni}(\mathrm{III})$ oxidation state by inhibiting the initiation of ligand exchange.

\section{Conclusions}

Here we report on the coordination of functionalized pyridines to $\mathrm{Ni}$ (III) metal centers and their impact on controlling $1 \mathrm{e}^{-}$vs $2 \mathrm{e}^{-}$oxidation pathways from $\mathrm{Ni}^{\mathrm{II}}(\mathrm{dtc})_{2}$ to $\left[\mathrm{Ni}^{\mathrm{IV}}(\mathrm{dtc})_{3}\right]^{+}$. When $\mathrm{Ni}^{\mathrm{II}}(\mathrm{dtc})_{2}$ is oxidized in the presence of pyridine ligands, either electrochemically or with a 
chemical oxidant, pyridine coordinated $\mathrm{Ni}$ (III) complexes are formed. Ligands which coordinate more weakly such as 3-Br-py form five-coordinate $\left[\mathrm{Ni}^{\mathrm{III}}(\mathrm{dtc})_{2}(\mathrm{py})\right]^{+}$species whereas more strongly coordinating ligands such as 4-MeO-py form six-coordinate trans-[Ni $\left.\mathrm{NII}^{\mathrm{III}}(\mathrm{dtc})_{2}(\mathrm{py})_{2}\right]^{+}$complexes. The small equilibrium between five- and six-coordinate complexes results in a mixture of monopyridine and bis-pyridine complexes for ligands of intermediate coordination strength such as underivatized pyridine. The formation of $\left[\mathrm{Ni}^{\mathrm{III}}(\mathrm{dtc})_{2}(\mathrm{~L})_{\mathrm{x}}\right]^{+}$complexes sheds light on the overall mechanism for $2 \mathrm{e}^{-}$oxidation from $\mathrm{Ni}^{\mathrm{II}}(\mathrm{dtc})_{2}$ to $\left[\mathrm{Ni}^{\mathrm{IV}}(\mathrm{dtc})_{3}\right]^{+}$which requires formation of a $\mathrm{Ni}^{\mathrm{III}}(\mathrm{dtc})_{3}$ intermediate. Through careful study of scan rate dependent cyclic voltammetry, we

conclude that coordination of pyridine to $\mathrm{Ni}(\mathrm{III})$ kinetically inhibits the formation of $\mathrm{Ni}^{\mathrm{III}}(\mathrm{dtc})_{3}$ by slowing down the ligand exchange reaction between $\left[\mathrm{Ni}^{\mathrm{III}}(\mathrm{dtc})_{2}(\mathrm{~L})_{\mathrm{x}}\right]^{+}$and $\mathrm{Ni}^{\mathrm{II}}(\mathrm{dtc})_{2}$. Despite this kinetic inhibition, formation of $\left[\mathrm{Ni}^{\mathrm{IV}}(\mathrm{dtc})_{3}\right]^{+}$was still found to be thermodynamically favorable as this product is ultimately formed either at the condition of slow scan rates for CV experiments or following chemical oxidation at room temperature. Further studies are underway using low temperature chemical oxidation to produce isolable $\mathrm{Ni}(\mathrm{III})$ complexes and $\{\mathrm{Ni}(\mathrm{III}), \mathrm{Ni}(\mathrm{II})\}$ dithiocarbamate dimers for structural study and further understanding of the ligand exchange mechanism.

\section{ASSOCIATED CONTENT}

Supporting Information available: Cyclic voltammetry, ${ }^{1} \mathrm{H}-\mathrm{NMR}$, DFT calculations, and electrochemical kinetic analysis

\section{Acknowledgments}

MRM and BHF acknowledge support from Auburn University as well as the National Science Foundation through a CAREER award CHE-1945160. We also thank Dr. Steven Mansoorabadi and Patrick Donnan for assistance with computational EPR studies. 


\section{References}

(1) Aoki, Y.; Takase, K.; Kiuchi, H.; Kowalski, D.; Sato, Y.; Toriumi, H.; Kitano, S.; Habazaki, H. In Situ Activation of a Manganese Perovskite Oxygen Reduction Catalyst in Concentrated Alkaline Media. J. Am. Chem. Soc. 2021, 143, 6505-6515.

(2) Bhatt, M. D.; Lee, J. Y. Advancement of Platinum (Pt)-Free (Non-Pt Precious Metals) and/or Metal-Free (Non-Precious-Metals) Electrocatalysts in Energy Applications: A Review and Perspectives. Energy Fuels 2020, 34, 6634-6695.

(3) Boschloo, G.; Hagfeldt, A. Characteristics of the Iodide/Triiodide Redox Mediator in DyeSensitized Solar Cells. Acc. Chem. Res. 2009, 42, 1819-1826.

(4) Huskinson, B.; Marshak, M. P.; Suh, C.; Er, S.; Gerhardt, M. R.; Galvin, C. J.; Chen, X.; Aspuru-Guzik, A.; Gordon, R. G.; Aziz, M. J. A Metal-Free Organic-Inorganic Aqueous Flow Battery. Nature 2014, 505, 195-198.

(5) Lin, K.; Chen, Q.; Gerhardt, M. R.; Tong, L.; Kim, S. B.; Eisenach, L.; Valle, A. W.; Hardee, D.; Gordon, R. G.; Aziz, M. J.; Marshak, M. P. Alkaline Quinone Flow Battery. Science 2015, 349, 1529-1532.

(6) Rowley, J. G.; Farnum, B. H.; Ardo, S.; Meyer, G. J. Iodide Chemistry in Dye-Sensitized Solar Cells: Making and Breaking I-I Bonds for Solar Energy Conversion. J. Phys. Chem. Lett. 2010, 1, 3132-3140.

(7) Strasser, P. Free Electrons to Molecular Bonds and Back: Closing the Energetic Oxygen Reduction (ORR)-Oxygen Evolution (OER) Cycle Using Core-Shell Nanoelectrocatalysts. Acc. Chem. Res. 2016, 49, 2658-2668.

(8) Alegría, A. E.; López, M.; Guevara, N. Thermodynamics of Semiquinone Disproportionation in Aqueous Buffer. J Chem Soc Faraday Trans 1996, 92, 4965-4968.

(9) Bour, J. R.; Camasso, N. M.; Meucci, E. A.; Kampf, J. W.; Canty, A. J.; Sanford, M. S. Carbon-Carbon Bond-Forming Reductive Elimination from Isolated Nickel(III) Complexes. J. Am. Chem. Soc. 2016, 138, 16105-16111.

(10) Kadish, K. M.; Bottomley, L. A.; Beroiz, D. Reactions of Pyridine with a Series of ParaSubstituted Tetraphenylporphyrincobalt and -Iron Complexes. Inorg. Chem. 1978, 17, 1124-1129.

(11) Schultz, J. W.; Fuchigami, K.; Zheng, B.; Rath, N. P.; Mirica, L. M. Isolated Organometallic Nickel(III) and Nickel(IV) Complexes Relevant to Carbon-Carbon Bond Formation Reactions. J. Am. Chem. Soc. 2016, 138, 12928-12934.

(12) Jude, H.; Krause Bauer, J. A.; Connick, W. B. An Outer-Sphere Two-Electron Platinum Reagent. J. Am. Chem. Soc. 2003, 125, 3446-3447.

(13) Pierce, D. T.; Geiger, W. E. Structural Consequences of Electron-Transfer Reactions. Part XX. Splitting of a Two-Electron Cyclic Voltammetric Wave into Its One-Electron Components: The (.Eta.-C6Me6)2Ru2+/+/0) Couples. J. Am. Chem. Soc. 1989, 111, 76367638.

(14) Waldie, K. M.; Ramakrishnan, S.; Kim, S.-K.; Maclaren, J. K.; Chidsey, C. E. D.; Waymouth, R. M. Multielectron Transfer at Cobalt: Influence of the Phenylazopyridine Ligand. J. Am. Chem. Soc. 2017, 139, 4540-4550.

(15) Bond, A. M.; Martin, R. L. Electrochemistry and Redox Behaviour of Transition Metal Dithiocarbamates. Coord. Chem. Rev. 1984, 54, 23-98.

(16) Hendrickson, A. R.; Martin, R. L.; Rohde, N. M. Dithiocarbamates of Nickel in the Formal Oxidation States I-IV. Electrochemical Study. Inorg. Chem. 1975, 14, 2980-2985. 
(17) Richburg, C. S.; Farnum, B. H. Influence of Pyridine on the Multielectron Redox Cycle of Nickel Diethyldithiocarbamate. Inorg. Chem. 2019, 58, 15371-15384.

(18) Lachenal, D. Electrochemical Behaviour of Nickel (II) and Ni (IV) N,NDiethyldithiocarbamates. Synthesis of a Nickel(IV) Species. Inorg. Nucl. Chem. Lett. 1975, 11, 101-106.

(19) Chung, Y.-C.; Tu, Y.-J.; Lu, S.-H.; Hsu, W.-C.; Chiu, K. Y.; Su, Y. O. Redox Potential Inversion by Ionic Hydrogen Bonding between Phenylenediamines and Pyridines. Org. Lett. 2011, 13, 2826-2829.

(20) Gosset, A.; Wilbraham, L.; Lachmanová, Š. N.; Sokolová, R.; Dupeyre, G.; Tuyèras, F.; Ochsenbein, P.; Perruchot, C.; de Rouville, H.-P. J.; Randriamahazaka, H.; Pospíšil, L.; Ciofini, I.; Hromadová, M.; Lainé, P. P. Electron Storage System Based on a Two-Way Inversion of Redox Potentials. J. Am. Chem. Soc. 2020, 142, 5162-5176.

(21) Hua, S.-A.; Cattaneo, M.; Oelschlegel, M.; Heindl, M.; Schmid, L.; Dechert, S.; Wenger, O. S.; Siewert, I.; González, L.; Meyer, F. Electrochemical and Photophysical Properties of Ruthenium(II) Complexes Equipped with Sulfurated Bipyridine Ligands. Inorg. Chem. 2020, 59, 4972-4984.

(22) Nomrowski, J.; Wenger, O. S. Exploiting Potential Inversion for Photoinduced Multielectron Transfer and Accumulation of Redox Equivalents in a Molecular Heptad. J. Am. Chem. Soc. 2018, 140, 5343-5346.

(23) Staley, P. A.; Lopez, E. M.; Clare, L. A.; Smith, D. K. Kinetic Stabilization of Quinone Dianions via Hydrogen Bonding by Water in Aprotic Solvents. J. Phys. Chem. C 2015, 119, 20319-20327.

(24) Bond, A. M.; Hendrickson, A. R.; Martin, R. L.; Moir, J. E.; Page, D. R. Electrochemical Reduction and Oxidation of Cobalt(III) Dithiocarbamates. Inorg. Chem. 1983, 22, 34403446.

(25) Chant, R.; Hendrickson, A. R.; Martin, R. L.; Rohde, N. M. Tris(Dithiocarbamato) Complexes of Iron(II), Iron(III), and Iron(IV). Electrochemical Study. Inorg. Chem. 1975, 14, 1894-1902.

(26) Bour, J. R.; Camasso, N. M.; Sanford, M. S. Oxidation of Ni(II) to Ni(IV) with Aryl Electrophiles Enables Ni-Mediated Aryl-CF 3 Coupling. J. Am. Chem. Soc. 2015, 137, 8034-8037.

(27) Camasso, N. M.; Sanford, M. S. Design, Synthesis, and Carbon-Heteroatom Coupling Reactions of Organometallic Nickel(IV) Complexes. Science 2015, 347, 1218-1220.

(28) Coucouvanis, D.; Fackler, J. P. Square-Planar Sulfur Complexes. VI.1 a Reactions of Bases with Xanthates, Dithiocarbamates, and Dithiolates of Nickel(II). Inorg. Chem. 1967, 6, 2047-2053.

(29) Avdeef, A.; Fackler, J. P.; Fischer, R. G. Structural Characterization of Tris(N,N-Di-nButyldithiocarbamato)Nickel(IV) Bromide. A Ni-S6 Complex with Unusual Chemical Properties. J. Am. Chem. Soc. 1970, 92, 6972-6974.

(30) Fackler, J. P.; Avdeef, A.; Fischer, R. G. Sulfur Chelates. XVI. Chemical Properties of Oxidized Nickel(II) Dithiocarbamates. The X-Ray Crystal Structure of Tris(N,N-Di-nButyldithiocarbamato)Nickel(IV) Bromide, NiC27 H54 N3 S6 Br. J. Am. Chem. Soc. 1973, 95, 774-782.

(31) Lee, C. M.; Chen, C. H.; Ke, S. C.; Lee, G. H.; Liaw, W. F. Mononuclear Nickel(III) and Nickel(II) Thiolate Complexes with Intramolecular S-H Proton Interacting with Both Sulfur 
and Nickel: Relevance to the [NiFe]/[NiFeSe] Hydrogenases. J. Am. Chem. Soc. 2004, 126, 8406-8412.

(32) Connelly, N. G.; Geiger, W. E. Chemical Redox Agents for Organometallic Chemistry. Chem. Rev. 1996, 96, 877-910.

(33) Hagen, W. R. Biomolecular EPR Spectroscopy; CRC Press, 2008.

(34) Saha, S.; Sahil, S. T.; Mazumder, Md. M. R.; Stephens, A. M.; Cronin, B.; Duin, E. C.; Jurss, J. W.; Farnum, B. H. Synthesis, Characterization, and Electrocatalytic Activity of Bis(Pyridylimino)Isoindoline Cu( II ) and Ni( II ) Complexes. Dalton Trans. 2021, 50, 926935.

(35) M. J. Frisch, G. W. Trucks, H. B. Schlegel, G. E. Scuseria, M. A. Robb, J. R. Cheeseman, G. Scalmani, V. Barone, G. A. Petersson, H. Nakatsuji, X. Li, M. Caricato, A. V. Marenich, J. Bloino, B. G. Janesko, R. Gomperts, B. Mennucci, H. P. Hratchian, J. V. Ortiz, A. F. Izmaylov, J. L. Sonnenberg, D. Williams-Young, F. Ding, F. Lipparini, F. Egidi, J. Goings, B. Peng, A. Petrone, T. Henderson, D. Ranasinghe, V. G. Zakrzewski, J. Gao, N. Rega, G. Zheng, W. Liang, M. Hada, M. Ehara, K. Toyota, R. Fukuda, J. Hasegawa, M. Ishida, T. Nakajima, Y. Honda, O. Kitao, H. Nakai, T. Vreven, K. Throssell, J. A. Montgomery, Jr., J. E. Peralta, F. Ogliaro, M. J. Bearpark, J. J. Heyd, E. N. Brothers, K. N. Kudin, V. N. Staroverov, T. A. Keith, R. Kobayashi, J. Normand, K. Raghavachari, A. P. Rendell, J. C. Burant, S. S. Iyengar, J. Tomasi, M. Cossi, J. M. Millam, M. Klene, C. Adamo, R. Cammi, J. W. Ochterski, R. L. Martin, K. Morokuma, O. Farkas, J. B. Foresman, and D. J. Fox. Gaussian, Inc., Wallingford CT, 2019.

(36) Weigend, F.; Ahlrichs, R. Balanced Basis Sets of Split Valence, Triple Zeta Valence and Quadruple Zeta Valence Quality for H to Rn: Design and Assessment of Accuracy. Phys. Chem. Chem. Phys. 2005, 7, 3297.

(37) E. F. Valeev. Libint: A Library for the Evaluation of Molecular Integrals of Many-Body Operators over Gaussian Functions; 2020.

(38) Susi Lehtola, Conrad Steigemann, Micael J. T. Oliveira, and Miguel A. L. Marques. Recent Developments in Libxc - A Comprehensive Library of Functionals for Density Functional Theory; 2018.

(39) Muckerman, J. T.; Skone, J. H.; Ning, M.; Wasada-Tsutsui, Y. Toward the Accurate Calculation of PKa Values in Water and Acetonitrile. Biochim. Biophys. Acta BBA Bioenerg. 2013, 1827, 882-891.

(40) Casasnovas, R.; Frau, J.; Ortega-Castro, J.; Salvà, A.; Donoso, J.; Muñoz, F. Absolute and Relative PKa Calculations of Mono and Diprotic Pyridines by Quantum Methods. J. Mol. Struct. THEOCHEM 2009, 912, 5-12.

(41) Emmenegger, F. P. A 1,10-Phenanthroline Adduct Complex of Bis(N,NDiethyldithiocarbamato)Nickel(II). Inorg. Chem. 1989, 28, 2210-2214.

(42) Vigee, G. S.; Watkins, C. L. Pyridine Adduct Complexes of Bis(N,NDithiocarbamate)Nickel(II). J. Inorg. Nucl. Chem. 1972, 34, 3936-3939.

(43) Bailey, S. I.; Ritchie, I. M.; Hewgill, F. R. The Construction and Use of Potential-PH Diagrams in Organic Oxidation-Reduction Reactions. J Chem Soc Perkin Trans 2 1983, No. 5, 645-652.

(44) De Castro, B.; Freire, C. EPR and Electrochemical Study of Nickel(III) Complexes of Bis(3,5-Dichlorosalicylaldehyde) o-Phenylenediimine. Evidence for Adduct Formation with Pyridines. Inorg. Chem. 1990, 29, 5113-5119. 
(45) Watson, M. B.; Rath, N. P.; Mirica, L. M. Oxidative C-C Bond Formation Reactivity of Organometallic Ni(II), Ni(III), and Ni(IV) Complexes. J. Am. Chem. Soc. 2017, 139, 3538.

(46) Mondal, P.; Lovisari, M.; Twamley, B.; McDonald, A. R. Fast Hydrocarbon Oxidation by a High-Valent Nickel-Fluoride Complex. Angew. Chem. Int. Ed. 2020, 59, 13044-13050.

(47) D’Accriscio, F.; Borja, P.; Saffon-Merceron, N.; Fustier-Boutignon, M.; Mézailles, N.; Nebra, N. C-H Bond Trifluoromethylation of Arenes Enabled by a Robust, High-Valent Nickel(IV) Complex. Angew. Chem. Int. Ed. 2017, 56, 12898-12902.

(48) Smith, S. M.; Rath, N. P.; Mirica, L. M. Axial Donor Effects on Oxidatively Induced Ethane Formation from Nickel-Dimethyl Complexes. Organometallics 2019, 38, 3602-3609.

(49) Smith, S. M.; Planas, O.; Gómez, L.; Rath, N. P.; Ribas, X.; Mirica, L. M. Aerobic C-C and C-O Bond Formation Reactions Mediated by High-Valent Nickel Species. Chem. Sci. 2019, 10, 10366-10372.

(50) Hansch, Corwin.; Leo, A.; Taft, R. W. A Survey of Hammett Substituent Constants and Resonance and Field Parameters. Chem. Rev. 1991, 91, 165-195. 


\section{Table of Contents Figure}

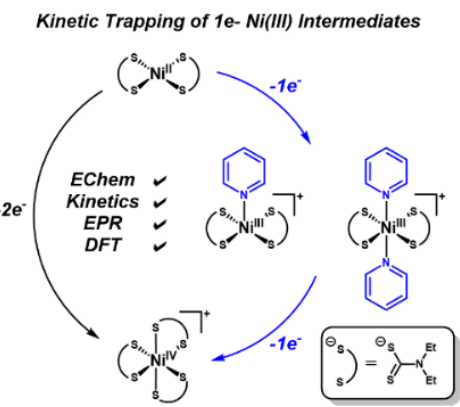

